\title{
Developing Brain-Strain-Based Scaling to Inform the Clinical Relevance of Mouse Models of Concussion Induced by Rotation
}

\author{
Xingyu Liu \\ Western University \\ Lihong Lu \\ Western University \\ Kewei Bian \\ Western University \\ Arthur Brown \\ Western University \\ Haojie Mao ( $\nabla$ hmao8@uwo.ca )
}

Western University

\section{Research Article}

Keywords: Traumatic brain injury (TBI), Scaling, Finite element model, Brain deformation, Brain strain

Posted Date: March 5th, 2021

DOI: https://doi.org/10.21203/rs.3.rs-271852/v1

License: (a) (i) This work is licensed under a Creative Commons Attribution 4.0 International License. Read Full License 
Developing Brain-Strain-Based Scaling to Inform the Clinical Relevance of Mouse Models of Concussion Induced by Rotation

Xingyu Liu ${ }^{1}$, MEng, Lihong Lu ${ }^{1}$, MESc, Kewei Bian ${ }^{1}$, MESc, Arthur Brown ${ }^{2} \mathrm{PhD}$, and Haojie Mao ${ }^{1,3, *}, \mathrm{PhD}$

1. Mechanical \& Materials Engineering, Faculty of Engineering, Western University, London ON Canada

2. Robarts Research Institute, Western University, London ON Canada

3. School of Biomedical Engineering, Western University, London ON Canada

*. Corresponding author: hmao8@uwo.ca, Tel: +1 519-661-2111 ext. 80364, Fax: +1 519661-3020 


\begin{abstract}
Background

Laboratory animal experiments are an invaluable tool for studying mild traumatic brain injury (mTBI)/concussion. Among them, rodent neurotrauma experiments have been most widely used, as transgenic and gene targeting technologies in mice allow us to test the roles of different genes in recovery from brain injury. Furthermore, the clinical relevance of rodent concussion studies can be improved by using these technologies to study concussions in animals that carry the human versions of genes known to play a role in neurological disease. However, delivering concussion injuries to the mice that are relevant to real-world human head impacts is challenging, as the mouse and human heads are dramatically different in shape and size. In the vast majority of mouse concussion experiments, the pathological and behavioral consequences of the injuries are evaluated without considering whether the injury model produces brain stretches (maximum principal strains) of the same magnitude as those experienced by human brains undergoing similar impacts.
\end{abstract}

\title{
Methods
}

We conducted a total of 201 computational simulations to understand both human and mouse brain strains that are directly linked to neuronal damage during closed-head concussive impacts. To represent real-world human head impacts we simulated mouse head impacts with durations of $1.5 \mathrm{~ms}$ (Type 1 scaling), followed by simulations with durations between 1 and $2 \mathrm{~ms}$ (Type 2), and finally, simulations with durations from 0.75 to $4.5 \mathrm{~ms}$ (Type 3) to develop scaling between human and mouse, as well as to reveal the predicted effects of small and large changes in impact durations on brain strain.

\section{Results}

Guided by these simulations we calculated that peak rotational velocities in mice could be achieved by scaling human peak rotational velocities with factors of 5.8, 4.6, and 6.8, for flexion/extension, lateral bending, and axial rotation, respectively, to reach equal brain strains between human and mouse. The effects of impact durations on scaling were also calculated and longer-duration mouse head impacts needed larger scaling factors to reach equal strain.

\section{Conclusions}

The scaling method will help us to create brain injury in the mouse with brain strain loading equivalent to those experienced in real-world human head impacts.

Keyword: Traumatic brain injury (TBI); Scaling; Finite element model; Brain deformation; Brain strain 


\section{Background}

Traumatic brain injury (TBI) is one of the leading causes of death and disability around the world, and occurs in more than 2.87 million people in America every year (1). Patients of TBI may suffer from physical, cognitive, social, emotional, and behavioral symptoms, and serious TBI can cause permanent disability and death (2). While symptoms in mild TBI (mTBI) patients typically resolve within 7 to 10 days post-injury (3), 15\% of mTBI patients go on to develop post-concussion syndrome and long-term cognitive impairment (4). Animal studies of mTBI are actively being pursued to understand the pathophysiological underpinnings of concussion and post-concussion syndrome.

There are various types of animal TBI experiments reported in the literature, partially because of the variability in human TBI that is being modeled. Researchers have focused on three models including open-skull cortical impact injury (CCI), open-skull fluid percussion injury (FPI) and closed-head weight drop-impact acceleration injury (5). Openskull TBI using the cortical impactor has been popular as it allows direct loading to the brain tissue and induces high brain strain above 0.30 to the underlying cortical layers (6). Open-skull TBI using the FPI also induces high strain up to $\sim 0.1$ and high pressure of approximately $180 \mathrm{kPa}(7)$. Despite the greater convenience of open skull TBI, closed-head TBI is considered more clinically relevant because it does not require a craniotomy (8) and real-world mTBI/concussions happen with closed-skull conditions. Hence, closed-head models have been prioritized in mTBI/concussion investigation with a majority of studies using rodents (9-11). The challenge is to ensure the mechanical loadings that rodent brains experienced in the laboratory setting are relevant to those experienced by human beings during real-world impacts.

It is well established that brain sizes are connected with mammalian physiology $(12,13)$. Thus, one method that has been used to scale brain injuries between species has focused on the effects of mass (14). Primates that have similar brain shape to human and Ommaya et al (14) reported that the risk of producing concussion in humans and primates is related to brain mass, which is determined by brain size. In studying blast injuries, Bowen et al (15) scaled the duration of the positive phase and the maximum reflected overpressure of air blast to get the same biological response among 13 species, by using scaling factors including body mass and ambient pressure. Wood et al (16) re-examined the allometric relationship between physiological manifestation and body mass across species, and came up with a new law that scales the duration of air blast using a ratio of reference mass to target animal mass using apnea data as injury evaluations.

There are also methods for scaling TBI between species that focus on parameters beyond brain mass. Takhounts et al (17) adopted a scaling law which scaled the amplitude and time of the loading condition to generate equal stress/velocity in two models of injury. Jean et al (18) focused on blast-induced TBI and emphasized that the human brain was more sensitive to blast than other mammalian species and proposed a scaling law taking relative acoustic impedance and surrounding protective structures into consideration. Saunders et al. developed a scaling rule based on the comparison between responses of two finite element (FE) models to fifteen available injury metrics (19). A recent study conducted by 
$\mathrm{Wu}$ et al. compared four scaling laws, including one self-developed, frequency-based method, by comparing the calculated brain strains using human, macaque, and baboon brain FE models (20).

Given the lack of scaling laws between human and mouse for mTBI studies, our goal was to devise a scaling factor to translate the kinematics of human head impacts to the kinematics in laboratory mouse impacts producing similar or equivalent degrees of brain strain. We first evaluated traditional mass-based scaling and equal stress/velocity scaling methods and found that they were not accurate in scaling human to mouse mTBI. We then compared strain-based injury metrics, including cumulative strain damage measure (CSDM)10 and average strain, to identify pairs of different rotational loading conditions predicted to result in similar brain strains in human and mouse (difference $<3 \%$ ). These analyses have led us to propose scaling laws in three rotational axes that will provide a useful and efficient reference when evaluating the clinical relevance of mouse mTBI experiments and when comparing the results of mouse mTBI experiments across laboratories (21).

\section{METHODS}

\section{The Finite Element Human Brain and Mouse Brain Models and Simulations}

The human FE brain model was developed from detailed computed tomography (CT) and MRI scans of an average adult male (21), using feature-based multi-block technology (22) to efficiently create high-quality hexahedral elements for the cerebrum, cerebellum, brainstem, corpus callosum, ventricles, and thalamus. The model was validated and exercised based on the experimental data of thirty-five cases and currently serves as one of the most used human head models to study brain responses (21). The mouse FE brain model includes the olfactory bulb, cerebral gray matter, corpus callosum, brainstem (midbrain, pons and medulla oblongata), cerebellum, lateral ventricle, 3rd ventricle, 4th ventricle, internal capsule, external capsule and part of spinal cord. Hexahedral meshes were used to ensure the accuracy of simulation. The mouse brain FE model has been used previously to successfully predict brain damage after experimental TBI $(23,24)$. All the simulations were processed in HyperMesh (Altair Engineering, Troy, MI) and LSPREPOST, and computed in LS-DYNA (Livermore Software Technology Corporation, Livermore, CA). Acceleration loading curves were adjusted based on the unit used by the models and applied to the center of gravity of each model using *BOUNDARY_PRESCRIBED_MOTION keyword to induce flexion, lateral bending, and axial rotation.

Brain model materials, rational of kinematic loading condition to the model, and postprocessing were consistent among the human and mouse. A linear viscoelastic (LVE) constitutive model for brain material properties was used in human and mouse finite element models. Although the human skull structures were modeled, these bony structures were treated as rigid for prescribed rotational loading, which is consistent with the loading condition to the mouse brain model for which a rigid skull layer was used to prescribe head 
rotations. The maximum principal (tensile) strain (MPS) was calculated for both the human and mouse brain, as brain tensile strains were found to be related to neuronal damage ( 25 , 26)

\section{Real-World-Relevant mTBI Loading Condition}

Extensive measurements of human head kinematics are available. Specifically, Rowson et al (27) created a large data set of human head six degrees of freedom acceleration of 1712 impacts by mean of installing accelerometers into the helmets of collegiate football players in 2007 and reported an average injury duration of $14 \mathrm{~ms}$ from 1712 cases. In 2012, Rowson et al (28) applied the same method to a study of 335 football players. In this study 300,977 sub-concussive and 57 concussive head impacts were detected and recorded. For concussive impacts, the average rotational acceleration was 5,022 $\mathrm{rad} / \mathrm{s}^{2}$. Based on the rotational head kinematics observed in these two experiments, and on the rotational acceleration versus time graph of National Football League (NFL) reconstructed impacts obtained using the six degrees of freedom (6 DOF) device (29) and Head Impact Telemetry (HIT) System (30), the acceleration loading condition for human mTBI is set to be half sinusoidal curve with the peak acceleration of 5,000 rad/s and duration of $10 \mathrm{~ms}$ and 15 ms. Based on previous simulations, a theoretical sinusoidal curve could be used to produce similar brain strains compared to the complex kinematics curves (31). Meanwhile, although head impacts induced both linear and rotational kinematics, it's found that rotational kinematics was responsible for generating over $95 \%$ of brain strain (31) and hence was the focus of this study.

\section{Evaluating Traditional Mass-Based and Equal Stress/Velocity Scaling Laws}

The human head kinematics was scaled to mouse head kinematics based on traditional laws, and then applied to the mouse FE brain model to quantify predicted strain responses.

\section{Mass-based scaling law 14,32$)$}

Brain mass-based scaling law focuses on the ratio of brain mass across species. Firstly, the mass of human brain model is 1256 grams (21), while the mouse brain model mass is 0.410 grams (24). According to the scaling law, the duration and the peak acceleration scaling factors were calculated based on the brain mass ratio between human and mouse as equations (1) (2) and (3) shown below

$$
\begin{gathered}
\lambda_{M}=\frac{M_{h}}{M_{m}}=\frac{1256}{0.410}=3063 \\
\lambda_{a}=\lambda_{M}{ }^{-\frac{2}{3}}=\lambda_{L}^{-2}=(3063)^{-\frac{2}{3}}=0.00474 \\
\lambda_{T}=\lambda_{M}{ }^{\frac{1}{3}}=\lambda_{L}=(3063)^{\frac{1}{3}}=14.5
\end{gathered}
$$

After this, the scaling factors were applied to human loading condition, the results are shown below 


$$
\begin{gathered}
\text { Peak acceleration for mouse }=\frac{5000(\text { human })}{\lambda_{a}}=\frac{5000}{0.00474}=1055 \mathrm{Krad} / \mathrm{s}^{2} \\
\text { Duration for mouse }=\frac{10(\text { human })}{\lambda_{T}}=\frac{10}{14.5}=0.6897 \approx 0.69 \mathrm{~ms}
\end{gathered}
$$

Equal stress/velocity scaling law $(17,33)$

This scaling law focuses on the ratio of brain geometry. The length ratio of brain equals cube root of mass ratio.

$$
\lambda_{L}=\lambda_{M}^{\frac{1}{3}}=(3063)^{\frac{1}{3}}=14.5
$$

Peak rot acceleration for mouse $=$

$$
5000(\text { human }) * \lambda_{L} * \lambda_{L}=5000 * 14.5 * 14.5=1055 \mathrm{krad} / \mathrm{s}^{2}
$$

$$
\text { Duration for mouse }=\frac{10(\text { human })}{\lambda}=\frac{10}{14.5}=0.69 \mathrm{~ms}
$$

In brief, despite different calculation procedures, the mass-based and equal-stress/equalvelocity-based models predicted the same kinematic parameters (peak acceleration and duration) would produce TBIs in the mouse equivalent to the average human TBI with a peak acceleration of $\sim 5000 \mathrm{Krad} / \mathrm{s}^{2}$ as reported by Rowson [29].

Developing Scaling Law Based on Brain Strain: Calculation of CSDM and Average Values (Type 1 with Fixed Time Duration)

In mTBI, one of the most common and vital pathologic mechanisms is axonal damage (34). Cater et al (25) calculated the cell loss of hippocampal slice cultures which experienced 30 different loading conditions expressed by the combinations of strain and strain rate and proved that the long-term responses of brain tissue to mechanical loading are correlated with strain instead of strain rate. Hence, we used the CSDM metric to calculate the loading to the whole brain. Equation (1) shows the formula for calculating the CSDM value.

$$
\mathrm{CSDM} x=\sum \text { volume of element experienced strain more than } x \%
$$

In an in vivo experiment, Bain et al (26) generated electrophysiological impairments by stretching guinea pig optical nerves with a final threshold strain of $18 \%$. Three days later the guinea pigs were euthanized, and their optic nerves evaluated for the presence of axonal bulbs. At an $18 \%$ strain threshold morphological and functional axonal damage was observed. In this study, a CSDM of 10 was chosen when comparing mechanical response of brain tissue between mouse and human to be certain of setting a lower threshold for a strain that likely produces pathology significant enough to be clinically relevant. Besides CSDM10, the average strain which roughly represents the loading to the entire brain was also used. The CSDM-predicted values for all cases are calculated through an in-house program previously described (35). 
The goal of mouse experiments was to yield kinematic curves generating the same CSDM values between the human and mouse. The entire process is described in Figure 1. The angular acceleration curves from real-world situations were simplified as sine curves and these curves were prescribed to human brain model to analyze brain tissue stretches (Figure 1). We then used the duration of mTBI in the mouse as 1.5 milliseconds (Type 1 scaling) as has been reported in mouse mTBI kinematic studies $(36,37)$ and started with an initial guess of mouse head rotational accelerations at $190 \mathrm{krad} / \mathrm{s}^{2}$. Then we predicted mouse model brain strain severity to the targeted human brain loadings, and adjusted rotational acceleration up or down based on the comparison, and solved the updated loading condition on mouse brain (Figure 1). Finally, scaling laws were evaluated and developed when equivalent strains of the human and mouse brains were reached (Figure 1).

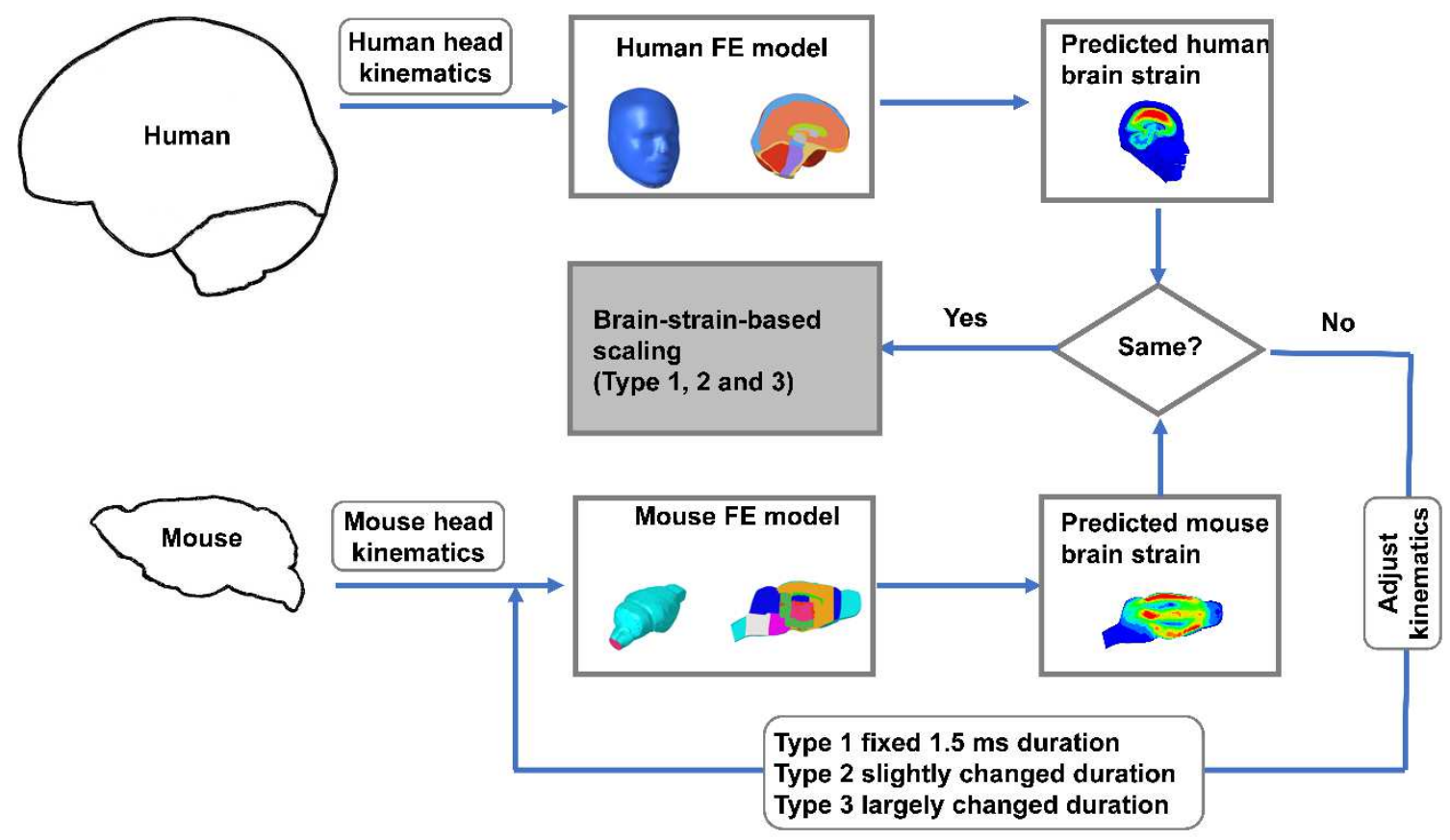

Figure 1 Workflow diagram represents methods in step how brain-strain-based scaling law was developed. Finite human brain and mouse brain finite element (FE) models were used to transfer head kinematics to brain strains. Three types of scaling with Type 1 indicating fixed $1.5 \mathrm{~ms}$ duration, Type 2 indicalting slightly changed duration, and Type 3 indicating larger changed duration.

Developing Scaling Law While Considering the Effect of Varying Durations (Type 2\&3)

In general, the same process (Figure 1) was adopted while in Type 2 scaling, time durations were slightly varied from 1 to $2 \mathrm{~ms}$, and in Type 3 scaling, time durations were largely varied from 0.75 to $4.5 \mathrm{~ms}$. 
Slightly Changed Time Duration (Type 2): Kinematic studies of head injury have shown that peak rotational velocity has a much stronger correlation with brain strain metrics such as CSDM, than either rotational acceleration or linear kinematics $(31,38-41)$. Hence, rotational velocity was chosen as the primary factor for scaling. A scaling law for rotational velocity will have a range of applications because an infinite combination of amplitudes and durations can produce the same velocity. As a result, the duration of an injury is also a significant factor when devising scaling laws. In order to make the scaling law practical and universal, to allow experimentalists to realize these kinematics parameters, a new group of simulations were conducted to explore applicable duration ranges. The acceptable tolerance was set to be less than a 3\% difference between human and mouse in terms of brain strain measured using CSDM10.

Mouse model with human brain material: Since brain material properties are agerelated (42) and brain material properties reported in the literature vary among researchers $(43,44)$, an independence test for brain materials was further conducted by applying human brain material properties to the mouse head model. This method can help understand the effect of shape and size without being affected by material diversity.

Largely Changed Time Durations (Type 3): Given the fact that there are laboratory mouse experiments performed with time durations that do not fall between 1 and 2 milliseconds $(9,45,46)$, the Type 3 study was conducted with an objective to understand how large changes in injury duration might affect the brain-strain-based scaling law. To minimize computational cost only 3 impact durations of $0.75,3$, and 4.5 milliseconds were simulated.

\section{RESULTS}

In total, 201 simulations were computed (Table 1): 3 for typical human mTBI-relevant head impacts, 2 for evaluating the current mass-based and equal stress/velocity scaling laws, 77 for developing scaling factors based on brain strain at an injury duration of $1.5 \mathrm{~ms}$ (Type 1), 75 for identifying the effect of small changes in injury duration (Type 2), and 22 for evaluating the effect of large changes injury duration (Type 3). A typical human or mouse head injury simulation took 2 CPUs approximately 8 hours to complete. All simulations terminated normally.

Table 1 Simulations breakdown. HMP: human material property

\begin{tabular}{cccc|c}
\hline Study & FE Model & $\begin{array}{c}\text { Rotational } \\
\text { axis }\end{array}$ & $\begin{array}{c}\text { Simulation } \\
\text { numbers }\end{array}$ & $\begin{array}{c}\text { Total } \\
\text { simulation } \\
\text { numbers }\end{array}$ \\
\hline \multirow{2}{*}{ Human mTBI } & Human model & $\begin{array}{c}\text { Flexion } \\
\text { Lateral } \\
\text { bending }\end{array}$ & 1 & \\
& Axial rotation & 1 & 3 \\
\hline
\end{tabular}




\begin{tabular}{|c|c|c|c|c|}
\hline $\begin{array}{l}\text { Evaluating } \\
\text { traditional } \\
\text { scaling laws }\end{array}$ & Mouse model $(23,24)$ & Flexion & 1 & 2 \\
\hline \multirow{6}{*}{$\begin{array}{l}\text { Type } 1 \text { - } \\
1.5 \mathrm{~ms}\end{array}$} & \multirow{3}{*}{ Mouse model } & Flexion & 12 & \multirow{6}{*}{$7^{\prime}$} \\
\hline & & $\begin{array}{l}\text { Lateral } \\
\text { hending }\end{array}$ & 19 & \\
\hline & & Axial rotation & 22 & \\
\hline & \multirow{3}{*}{$\begin{array}{l}\text { Mouse model with } \\
\text { HMP }\end{array}$} & Flexion & 8 & \\
\hline & & Lateral & 9 & \\
\hline & & $\begin{array}{c}\text { bending } \\
\text { Axial rotation }\end{array}$ & $\begin{array}{l}9 \\
7\end{array}$ & \\
\hline \multirow{6}{*}{$\begin{array}{l}\text { Type } 2 \text { - } \\
\text { duration } \\
\text { slightly changed }\end{array}$} & \multirow{3}{*}{ Mouse model } & Flexion & 10 & \multirow{6}{*}{75} \\
\hline & & $\begin{array}{l}\text { Lateral } \\
\text { bending }\end{array}$ & 16 & \\
\hline & & Axial rotation & 10 & \\
\hline & \multirow{3}{*}{$\begin{array}{l}\text { Mouse model with } \\
\text { HMP }\end{array}$} & Flexion & 12 & \\
\hline & & $\begin{array}{l}\text { Lateral } \\
\text { hendino }\end{array}$ & 12 & \\
\hline & & Axial rotation & 15 & \\
\hline $\begin{array}{l}\text { Type } 3 \text { - } \\
\text { duration largely } \\
\text { changed }\end{array}$ & Mouse model & $\begin{array}{c}\text { Flexion } \\
\text { Lateral } \\
\text { bending } \\
\text { Axial rotation }\end{array}$ & $\begin{array}{l}11 \\
22 \\
11\end{array}$ & 44 \\
\hline Total & & & & 201 \\
\hline
\end{tabular}

\section{Evaluation of Traditional Scaling Laws}

The typical loading condition for mTBI and the corresponding loading condition scaled from it were applied to the human and mouse brain FE models. The CSDM10 metric, which quantified the volume of brain elements experiencing principal strain above 0.10 , was used to determine the severity of brain injury. After simulations, using the mass-based or the equal stress/velocity-based laws the CSDM10 in the human brain FE model was found to be 0.740 , while the CSDM10 in the mouse brain FE model and human-material mouse brain model of 0.954 and 0.947 respectively. Accordingly, mouse brain showed much larger high strain areas and model materials did not affect the observation that applying traditional scaling laws to develop mouse head impacts would have significantly increased injury severity (Figure 2). 


\section{Human brain strain}
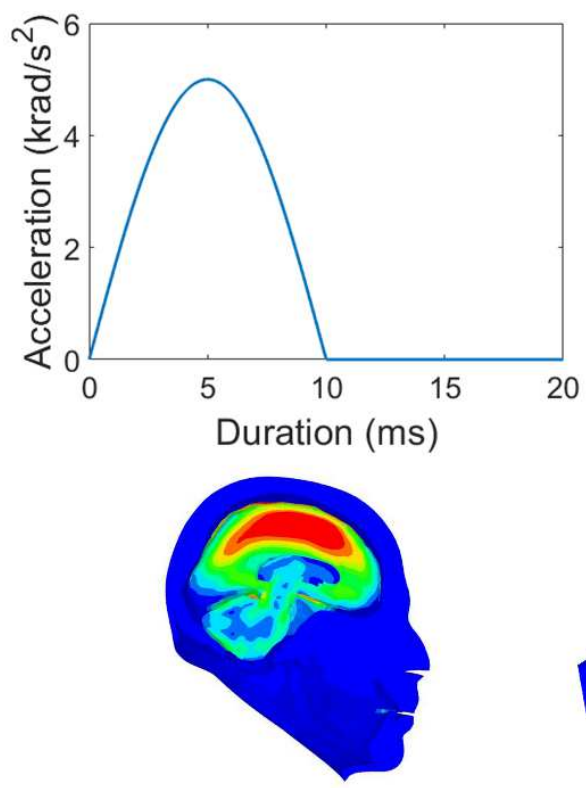

CSDM10 $=0.740$
Brain mass-based scaling law \& Equal stress/velocity scaling law

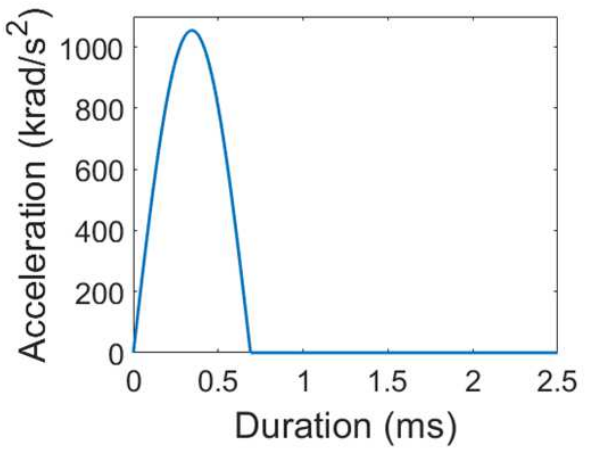

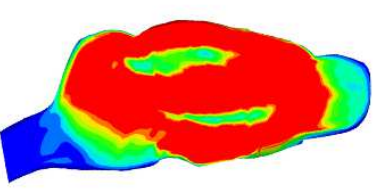

Original mouse brain model

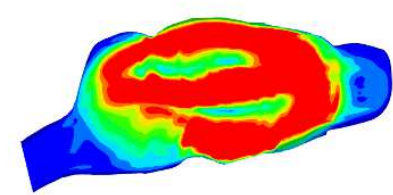
mouse brain model
Human-material

Figure 2 Evaluation of current scaling law. Applying traditional scaling induced larger strains in the mosue brain.

\section{Scaled Mouse Brain Strain Data}

Simulations were made of 78 mouse head rotations which were then used to calculate the relations between peak rotational acceleration and duration that defined rotational acceleration curves applied to drive FE brain models, peak rotational velocity that was calculated by integrating rotational acceleration over time, and mouse brain strain. First, our simulations demonstrated that the CSDM10-based brain injury severity had a strong positive correlation with peak rotational velocity (R-squared $=0.98$, Figure 3a). Constrained to the same-rotational-velocity data group, the CSDM10 value has a negative correlation with impact duration (R-squared $=0.99$, Figure $3 \mathrm{c}$ ) while the peak velocity remained the same. Both rules indicated that longer durations and smaller peak rotational 
accelerations induced less damage. The same trends were also found in a modified mouse model with human brain material properties (21) (R-squared $=0.97$ and 0.99 respectively, Figure $3 \mathrm{a} \& \mathrm{c})$.

\section{Peak rotational velocity VS. Brain strain responses}
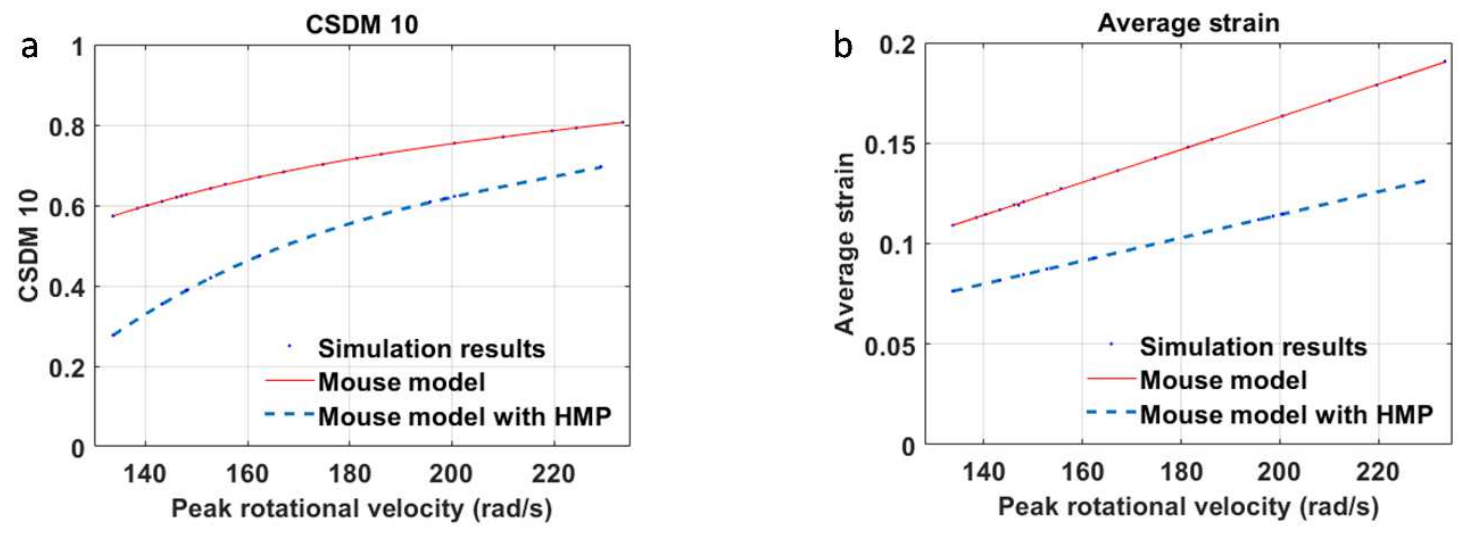

Duration VS. Brain strain responses
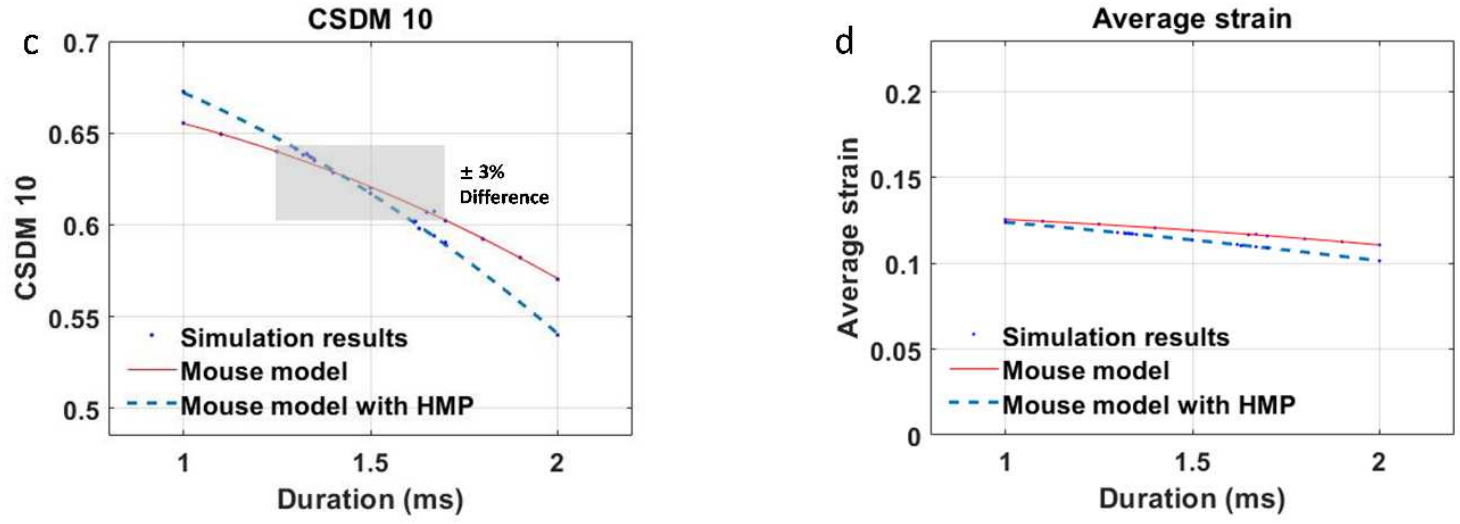

Figure 3 Relations between CSDM10, velocity and loading duration. The strain contour diagrams in the middle come from mouse model simulation results. (a) \& (b) Model predicted CSDM10 and average strain increases with peak rotational velocity when the duration is set to be constant as $1.5 \mathrm{~ms}$ in both the mouse model and the modified mouse model. (c) \& (d) Model predicted CSDM10 and average strain slightly decreases with the peak rotational velocity being set to be constant as $146 \mathrm{rad} / \mathrm{s}$ in the mouse model and 199 $\mathrm{rad} / \mathrm{s}$ in the modified mouse model.

The scaling factor shows the ratio of peak velocity between loading conditions of mouse and human brain model. The scaling factors are different for different rotation directions as predicted. The largest scaling factor is 6.8 for axial rotation, followed by 5.8 for flexion and 4.6 for lateral bending (Table 2). 
Table 2 Simulation results of mouse brain model and scaling factors between human and mouse.

\begin{tabular}{|c|c|c|c|c|c|c|}
\hline \multicolumn{5}{|c|}{ Mouse } & \multicolumn{2}{|c|}{ Human } \\
\hline Orientation & $\begin{array}{c}\text { Peak rot } \\
\text { acceleration } \\
\text {-duration }^{\mathrm{a}}\end{array}$ & $\begin{array}{l}\text { Peak rot } \\
\text { velocity }^{\text {b }}\end{array}$ & CSDM10 & $\begin{array}{c}\text { Scaling } \\
\text { factor } \\
(\mathbf{M} / \mathbf{H})^{\mathbf{c}}\end{array}$ & $\begin{array}{l}\text { Peak rot } \\
\text { velocity }\end{array}$ & CSDM10 \\
\hline \multirow{3}{*}{ Flexion } & $173-1.65$ & & 0.72 & & & \\
\hline & $193-1.5$ & 184 & 0.74 & 5.8 & 31.8 & 0.74 \\
\hline & $238-1.2$ & & 0.77 & & & \\
\hline \multirow{3}{*}{$\begin{array}{l}\text { Lateral } \\
\text { bending }\end{array}$} & $135-1.7$ & & 0.60 & & & \\
\hline & $153-1.5$ & 146 & 0.62 & 4.6 & 31.8 & 0.62 \\
\hline & $184-1.25$ & & 0.64 & & & \\
\hline \multirow{3}{*}{$\begin{array}{l}\text { Axial } \\
\text { rotation }\end{array}$} & $180-1.87$ & & 0.77 & & & \\
\hline & $225-1.5$ & 215 & 0.80 & 6.8 & 31.8 & 0.80 \\
\hline & $355-0.95$ & & 0.82 & & & \\
\hline
\end{tabular}

Note. ${ }^{\mathrm{a}}$ The unit is krad $/ \mathrm{s}^{2}-\mathrm{ms} ;{ }^{\mathrm{b}} \mathrm{The}$ unit is $\mathrm{rad} / \mathrm{s} ;{ }^{\mathrm{c}} \mathrm{M}=$ Mouse (Peak rotational velocity), $\mathrm{H}=$ Human (Peak rotational velocity), Scaling factor is the ratio between mouse head peak rotational velocity and human head peak rotational velocity.

\section{Effect of Mouse Brain Material}

As for mouse brain FE model with human brain materials, the scaling factors become larger to 7.5, 6.3 and 7.1 for flexion, lateral bending, and axial rotation respectively (Table 3).

Table 3 Simulation results of human-material mouse brain model and scaling factors between human and mouse.

\begin{tabular}{|c|c|c|c|c|c|c|}
\hline \multicolumn{5}{|c|}{ Mouse } & \multicolumn{2}{|c|}{ Human } \\
\hline Orientation & $\begin{array}{c}\text { Peak rot } \\
\text { acceleration } \\
\text {-duration }\end{array}$ & $\begin{array}{l}\text { Peak rot } \\
\text { velocity }^{\text {b }}\end{array}$ & CSDM10 & $\begin{array}{c}\text { Scaling } \\
\text { factor } \\
(\mathrm{M} / \mathrm{H})^{\mathrm{c}}\end{array}$ & $\begin{array}{l}\text { Peak rot } \\
\text { velocity }\end{array}$ & CSDM10 \\
\hline \multirow{3}{*}{ Flexion } & $231-1.62$ & & 0.72 & & & \\
\hline & $250-1.5$ & 239 & 0.74 & 7.5 & 31.8 & 0.74 \\
\hline & $274-1.37$ & & 0.76 & & & \\
\hline \multirow{3}{*}{$\begin{array}{l}\text { Lateral } \\
\text { bending }\end{array}$} & 193-1.62 & & 0.60 & & & \\
\hline & $208-1.5$ & 199 & 0.62 & 6.3 & 31.8 & 0.62 \\
\hline & 233-1.34 & & 0.64 & & & \\
\hline \multirow{3}{*}{$\begin{array}{l}\text { Axial } \\
\text { rotation }\end{array}$} & $189.5-1.86$ & & 0.77 & & & \\
\hline & $235-1.5$ & 224 & 0.80 & 7.1 & 31.8 & 0.80 \\
\hline & $405-0.87$ & & 0.82 & & & \\
\hline
\end{tabular}

Note. ${ }^{\mathrm{a} T h e}$ unit is $\mathrm{krad} / \mathrm{s}^{2}-\mathrm{ms} ;{ }^{\mathrm{b}}$ The unit is $\mathrm{rad} / \mathrm{s} ;{ }^{\mathrm{c}} \mathrm{M}=$ Mouse (Peak rotational velocity), $\mathrm{H}=$ Human (Peak rotational velocity), Scaling factor is the ratio between mouse head peak rotational velocity and human head peak rotational velocity. 
Meanwhile, the average strain showed a similar trend as CSDM did (R-squared $>0.99$, Figure 3). The comparison of average strain results from human brain FE model, mouse brain FE model, and mouse brain FE model using human brain material materials are compared in Figure 4. In general, the differences were less than $10 \%$ during flexion and lateral bending modes.

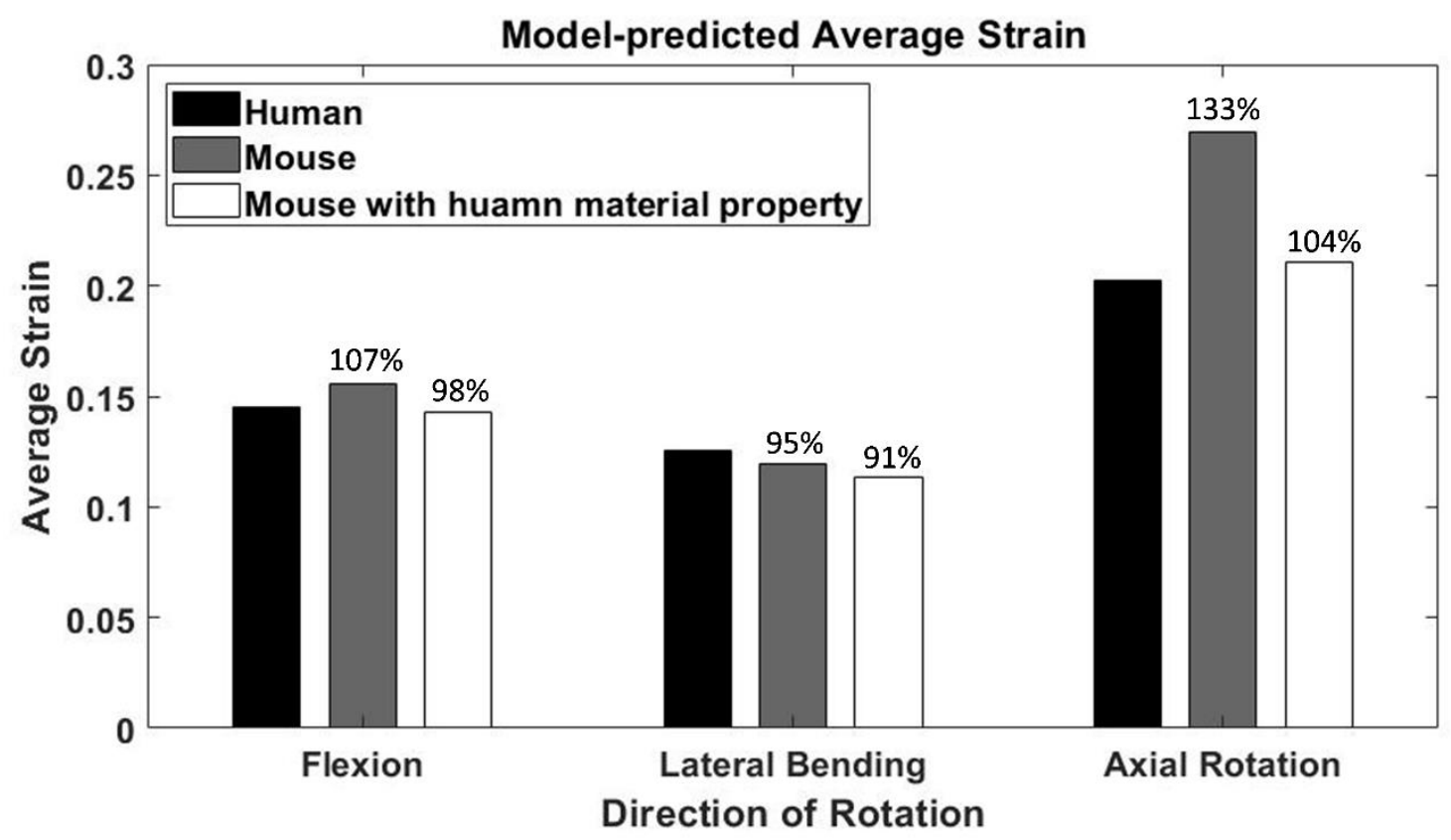

Figure 4 The comparison of predicted average strain between human, mouse and modified mouse models. The average strain around 0.15 indicates the injury severity is mild.

\section{Strain distribution predicted by the human brain FE model}

In simulations for head impacts around the $\mathrm{Y}$ axis (causing flexion), the area that experienced MPS greater than 0.10 was the cortex with a maximum strain of 0.54 . Additional scattered strains were also seen around the surface of corpus callosum (0.23) and brainstem (0.31), with the cerebellum being less stretched (0.19) (Figure 5a and d). In simulations for lateral bending, the corpus callosum, thalamus, basal ganglia, cortex and cerebellum all experienced MPS larger than 0.1. The corpus callosum and cortex reached a maximum strain of 0.48 and 0.44 respectively (Figure 5b). Lastly in simulations of injuries causing axial rotation, the most severe injury of all three cases, nearly all parts of the brain were affected. The cortex suffered the largest strain (0.74) at its surface. The corpus callosum had a strain of 0.37 and the hippocampus stood out in this loading condition with a strain of 0.46 . The highest stretch always took place at the cortex except in lateral bending for which the corpus callosum experienced the highest strain (Figure 5c). Strain distribution predicted by the mouse brain FE model 
Unlike the human brain FE model, MPS distributed in the mouse FE model showed a figure-eight pattern for simulations of injuries causing flexion (Figure 5a and $\mathrm{d}$ ). The highest MPS (0.47) can be found in the cerebral cortex. The second highest strain was in cerebellum (0.36). Brain stem, olfactory and pons experienced relatively small strains. In simulations of injuries causing lateral bending, the cortex had the highest strain of 0.38 , while there were lower strains in the cerebellum (0.33) and thalamus (0.32) (Figure 5b). The worst damage among all mouse cases was predicted in simulations of injuries causing axial rotations, where the cortex and cerebellum had MPS of 0.8 and 0.75 , respectively, but only a few portions of thalamus and brain stem experiencing MPS over 0.10. Distributions of strain for simulations of injury were not significantly different between the mouse brain FE model and the mouse brain FE model using human brain material with the exception that strains were lower in injury simulations with axial rotation (Figure 5c).
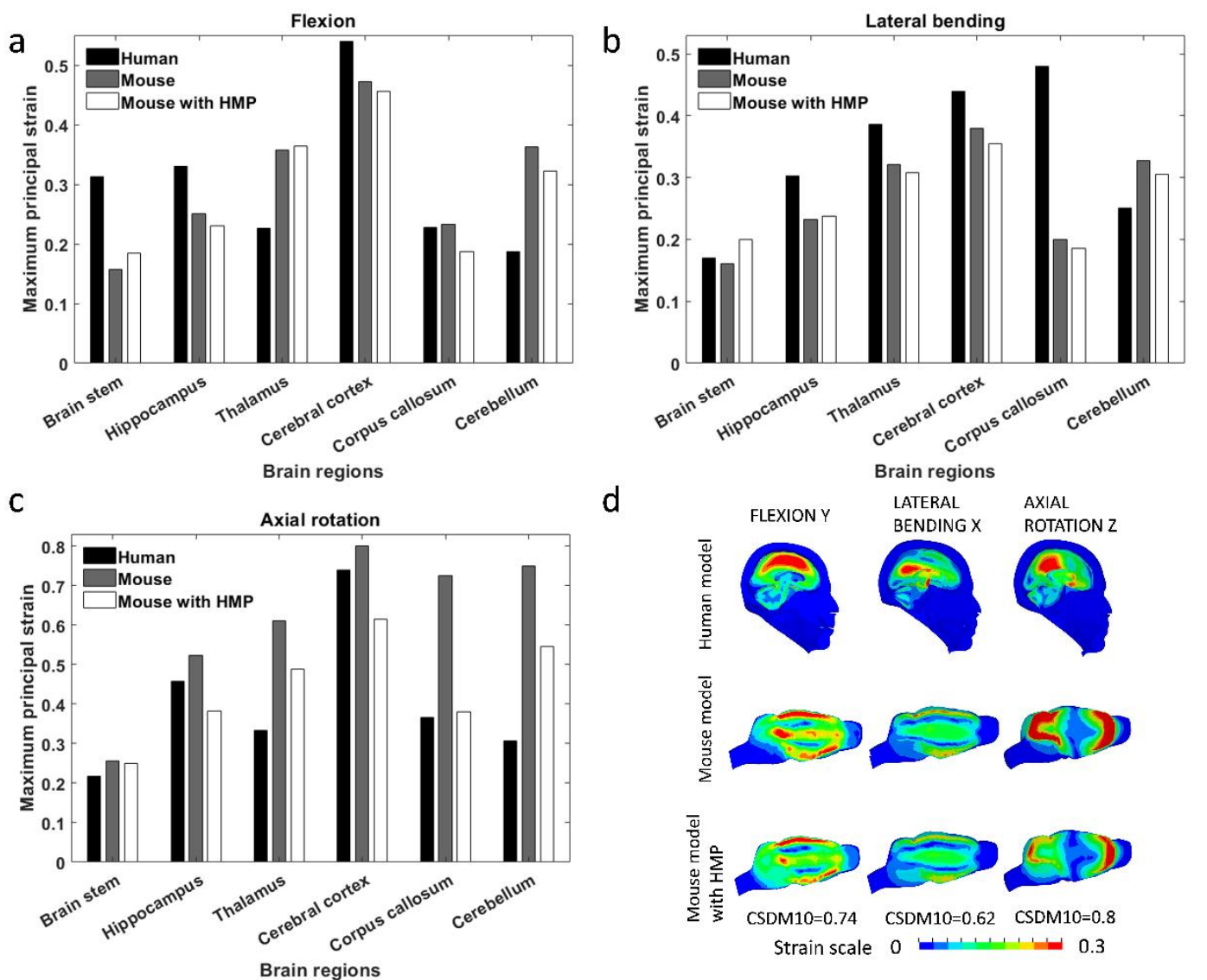

Figure 5 (a)(b)(c) Maximum principal strains for various brain regions in three rotational orientations including flexion, lateral bending, and axial rotation, respectively. (d) Predicted strain contour diagram of three models in three rotational orientations. The Effect of Varying Durations 
In reaching less than 3\% difference of brain strain (CSDM10) between human and mouse brain, a duration of 1.37 to $1.62 \mathrm{~ms}$ was found for flexion loading, a duration of 1.34 to $1.62 \mathrm{~ms}$ was found for lateral bending, and a duration of 0.97 to $1.82 \mathrm{~ms}$ for axial rotation. With the same rotational velocity, the longer the duration, which corresponded to lesser peak acceleration, the smaller area in the brain would experience high-level strain (Figure $3 \mathrm{c}$ and $\mathrm{d})$.

Results from simulations using flexion loading and durations of $0.75 \mathrm{~ms}, 1.5 \mathrm{~ms}, 3 \mathrm{~ms}$, and $4.5 \mathrm{~ms}$ demonstrated a linear correlation between duration and scaling factors with a scope of 0.82 (R-squared $=0.99$, Figure 6a). Under lateral bending, a similar linear relation was shown with a slope of $0.66(\mathrm{R}$-squared $=0.99)$ while under axial rotation, scaling factors were similar for durations $1.5,3.0$ and $4.5 \mathrm{~ms}$ but smaller for a duration of $0.75 \mathrm{~ms}$, forming a nonlinear relationship between duration and scaling factor. In general, larger scaling factors were calculated for loadings with a longer impact duration (Figure 6b). 
a

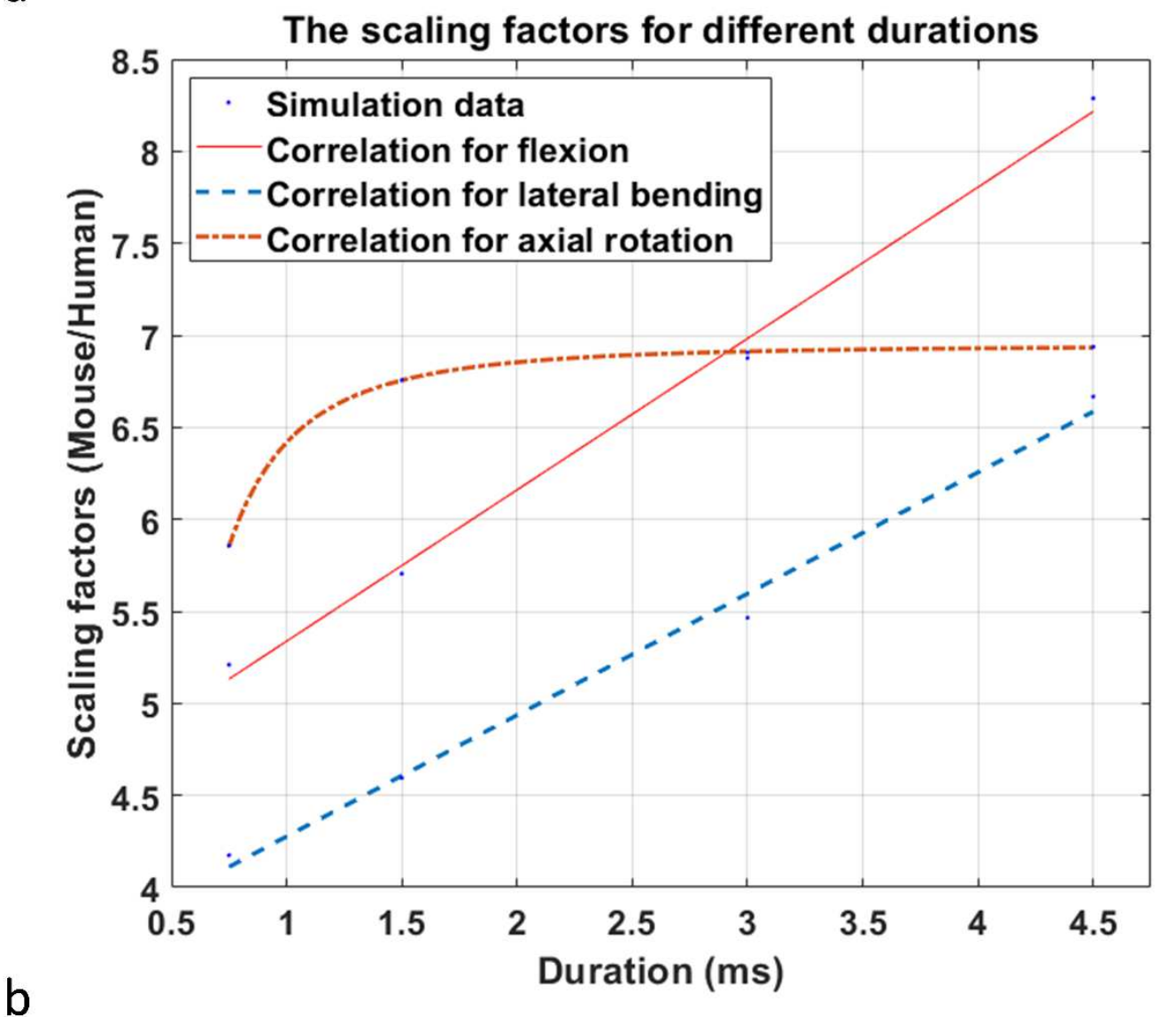

\begin{tabular}{c|c|c|c|c|c}
\hline \multicolumn{2}{c|}{ Duration (ms) } & 0.75 & 1.5 & 3 & 4.5 \\
\hline \multirow{2}{*}{$\begin{array}{c}\text { Scaling } \\
\text { factor } \\
(\mathrm{M} / \mathrm{H})\end{array}$} & $\mathrm{F}^{\mathrm{b}}$ & 5.2 & 5.8 & 6.9 & 8.3 \\
\cline { 2 - 6 } & $\mathrm{L}^{\mathrm{c}}$ & 4.2 & 4.6 & 5.5 & 6.7 \\
\cline { 2 - 6 } & $\mathrm{A}^{\mathrm{d}}$ & 5.9 & 6.8 & 6.9 & 6.9 \\
\hline
\end{tabular}

Note. ${ }^{\mathrm{a}} \mathrm{M}=$ Mouse (Peak rotational velocity), $\mathrm{H}=$ Human (Peak rotational velocity); ${ }^{b} \mathrm{~F}=$ Flexion; ${ }^{\mathrm{c}} \mathrm{L}=$ Lateral bending; ${ }^{\mathrm{d}} \mathrm{A}=$ Axial rotation

Figure 6 The effect of duration during flexion loading. a) Scaling number increases linearly with duration. b) Summary of scaling factors for different durations.

\section{DISCUSSION}

Mouse experiments are needed to study the pathophysiology of mTBI, but such studies are hampered by a lack of understanding of how laboratory impacts to the outside of the head 
translate into brain strain inside the head. This lack of understanding makes it difficult to draw consistent correlations between laboratory mouse head impacts causing mTBI and the observed pathological and behavioral consequences from human head impacts. It also makes it difficult to evaluate the clinical relevance of the mouse mTBI models in use. Meanwhile, traditional scaling laws that did not take account the shape differences between mouse and human brains were found invalid based on our data. To fill this gap, we simulated head impacts using human and mouse brain FE models to understand the internal brain strains, which are the direct cause of neuronal and functional damage and have been quantified in vitro $(47,48)$. These analyses have led to 3 findings. First, we found that peak rotational velocity could serve as an efficient metric for scaling. Second, we developed direction-specific scaling laws, as the same rotational kinematics could result in various degrees of brain injury when applied to different rotational directions $(49,50)$. Moreover, the geometry difference between human and mouse brain complicated the process of finding human-to-mouse scaling parameters. Our data supported measuring and scaling mouse head rotational velocities, which allow us to generate strain (CSDM10) in the mouse brain similar to that in the human brain with differences less than $3 \%$. We calculated scaling factors 5.8 for scaling up human-head rotational velocities during flexion/extension loading, 4.6 for lateral bending, and 6.8 for axial rotation. Lastly, we investigated the applicable time duration range of developed laws and reported potential changes for shorter or longer mouse head impact durations. For example, the scaling factor changed from 5.8 for 1.5 -ms impact to 8.3 for 4.5 -ms impact. To the best of our knowledge, this study serves as a unique investigation correlating laboratory mouse brain strain to human brain strain, and provides a useful reference for mouse mTBI experiments.

We focused on simulating rotational kinematics of the closed-head impacts in this study, as our previous data supported that rotation was responsible for more than $95 \%$ of strains developed in the brain (31). Doing so, we were able to capture the most important strainrelated kinematics. In laboratory closed-head impact tests, no matter where the animal heads were hit, the induced linear and rotational kinematics were the culprits that induced brain responses and led to brain damage, especially for mild TBI impacts for which skull deformation is limited. Meanwhile, open-skull laboratory neurotrauma loadings such as CCI and FPI are still widely used, for which part of the skull was removed and mouse cortical brain could experience strains up to 0.3 and higher in CCI (6) and around 0.10 in FPI (7). The focus on rotational kinematics in this study was consistent with mouse model such as CHIMERA (9) and swine models, both focusing on inducing head rotations (51, 52). Also, our scaling method was based on brain MPS and a limitation of this study needs to be acknowledged as the lack of investigation into damage related to the axon and vascular directions, which remain to be further investigated in the future.

Scaling studies have been conducted with the understanding of various degrees of brain injury $(49,50)$ and the acknowledgement of the geometry difference between human and animal brain. One example is to use natural frequency of the brain through a single-degreeof-freedom mechanical model (40). One of the challenges is in such a method is to understand the frequency values which have diverse features (53). On the other hand, the widely used mass-based scaling or same-stress-same-velocity approaches $(14,17)$ were 
found to generate different strains between the mouse and human brains, partially due to the huge geometrical differences between human and mouse brains, and hence found not fit for scaling mTBI mouse experiments. The brain strain or peak overpressure as a metric to evaluate the severity of blunt and blast-induced impact was used in the field $(16,20)$, as these brain internal responses directly cause injuries. In our work, the MPS-based CSDM was used to develop the unique mouse-to-human scaling laws.

The fixed impact duration of around $1.5 \mathrm{~ms}$ used in this study for Type 1 scaling has been used in models of rat TBI (37). In addition, several rotational injury devices have been developed to induce mTBI in brain by exerting rotation (54-56). In these studies, mouse post-injury behavior was examined through various methods such as elevated plus maze and rotarod performance test. As various injury devices deliver different impact durations, we have expanded our scaling laws to accommodate both slightly changed durations (Type 2) and largely changed durations (Type 3). In all these Type 1, 2, and 3 scaling laws, the agreements between human and mouse brain strains were reached. Table 4 summarizes example cases of using the scaling laws developed in this study. For example, to induce mouse head impacts that mimics a $5 \mathrm{krad} / \mathrm{s}^{2} \& 10-\mathrm{ms}$ flexion loading to the human head, various combinations of laboratory settings could be used such as $193 \mathrm{krad} / \mathrm{s}^{2} \& 1.5 \mathrm{~ms}$, $347 \mathrm{krad} / \mathrm{s}^{2} \& 0.75 \mathrm{~ms}, 115 \mathrm{krad} / \mathrm{s}^{2} \& 3.0 \mathrm{~ms}$, and $92 \mathrm{krad} / \mathrm{s}^{2} \& 4.5 \mathrm{~ms}$.

Table 4 Example mouse head kinematics using calculated scaling factor.

\begin{tabular}{|c|c|c|c|c|c|}
\hline \multirow[t]{3}{*}{ Orientation } & \multirow{3}{*}{$\begin{array}{l}\text { Human } \\
\text { head } \\
\text { Peak rot } \\
\text { velocity }^{\mathrm{a}}\end{array}$} & \multicolumn{4}{|c|}{$\begin{array}{l}\text { Mouse head kinematics combinations } \\
\text { Mouse head } \\
\text { rot acceleration - duration - peak rot velocity }\end{array}$} \\
\hline & & \multicolumn{4}{|c|}{ Duration (ms) } \\
\hline & & $1-2$ & 0.75 & 3.0 & 4.5 \\
\hline Flexion & 31.8 & $\begin{array}{l}173-1.65-184 \\
193-1.5-184 \\
238-1.2-184\end{array}$ & $347-0.75-166$ & $115-3.0-220$ & $92-4.5-264$ \\
\hline $\begin{array}{l}\text { Lateral } \\
\text { bending }\end{array}$ & 31.8 & $\begin{array}{c}135-1.7-146 \\
153-1.5-146 \\
184-1.25-146 \\
\end{array}$ & $278-0.75-133$ & $91-3-174$ & $74-4.5-212$ \\
\hline $\begin{array}{c}\text { Axial } \\
\text { rotation }\end{array}$ & 31.8 & $\begin{array}{l}180-1.87-215 \\
225-1.5-215 \\
355-0.95-215\end{array}$ & $390-0.75-186$ & $115-3-220$ & $77-4.5-221$ \\
\hline
\end{tabular}

Note. ${ }^{\mathrm{a}}$ The unit is $\mathrm{rad} / \mathrm{s}-\mathrm{ms}$; ${ }^{\mathrm{b}} \mathrm{The}$ unit is $\mathrm{krad} / \mathrm{s}^{2}-\mathrm{ms}-\mathrm{rad} / \mathrm{s}$.

\section{CONCLUSIONS}

To facilitate developing and understanding laboratory closed-head mouse mTBI experiments, which are designed to study human mTBI, we conducted a total of 201 simulations to investigate mouse and human brain strains during various impacts. Our data supported scaling human rotational velocity by 5.8, 4.6, and 6.8 under flexion/extension, lateral bending, and axial rotation, respectively, for mouse laboraotry experiments. We also 
found that traditionally used mass-based or same-stress-same-velocity scaling laws did not apply to human-to-mouse brain injury scaling. Meanwhile, it should be noted that the application of above scaling parameters best fit for mouse head impact durations of 1 to 2 ms, while with longer impact durations, larger scaling numbers are needed.

\section{Acknowledgements}

We acknowledge NSERC, New Frontiers in Research Fund - Exploration (NFRF-E), and Canada Research Chairs program for support.

\section{Declarations}

We declare that all authors contributed to the paper and agreed on submission. There is no conflict of interest for any authors. Ethics approval was not needed for this computational work. Funding information has been appropriately acknowledged.

Modelling data and detailed data are available upon request. All authors consent to publish the work presented in this manuscript.

\section{Availability of data and materials}

The datasets used and/or analyzed during the current study are available from the corresponding author on reasonable request.

\section{Competing interests}

There is no conflict of interest for any authors.

\section{Funding}

The authors acknowledge support from the New Frontiers in Research Fund - Exploration, Canada Research Chairs and NSERC.

\section{Contributions}

XYL, LHL, KWB and HJM designed the study, XYL performed the simulations and analyzed the results in collaboration with HJM. XYL and HJM drafted the manuscript. AB contributed to evaluation of the simulation data and preparation of the manuscript. All the authors read and approved the final manuscript.

\section{Author's information}

\section{Affiliations}

Xingyu Liu ${ }^{1}$, MEng, Lihong Lu ${ }^{1}$, MESc, Kewei Bian ${ }^{1}$, MESc, Arthur Brown ${ }^{2} \mathrm{PhD}$, and Haojie $\mathrm{Mao}^{1,3}, \mathrm{PhD}$

1. Mechanical \& Materials Engineering, Faculty of Engineering, Western University, London ON Canada

2. Robarts Research Institute, Western University, London ON Canada

3. School of Biomedical Engineering, Western University, London ON Canada 


\section{References}

1. Peterson AB, Xu L, Daugherty J, Breiding MJ. Surveillance report of traumatic brain injury-related emergency department visits, hospitalizations, and deaths, United States, 2014. 2019.

2. Kerr ZY, Marshall SW, Harding HP, Jr., Guskiewicz KM. Nine-year risk of depression diagnosis increases with increasing self-reported concussions in retired professional football players. Am J Sports Med. 2012;40(10):2206-12.

3. McCrory P, Meeuwisse WH, Aubry M, Cantu B, Dvořák J, Echemendia RJ, et al. Consensus statement on concussion in sport: the 4th International Conference on Concussion in Sport held in Zurich, November 2012. British Journal of Sports Medicine. $2013 ; 47(5): 250$.

4. McInnes K, Friesen CL, MacKenzie DE, Westwood DA, Boe SG. Mild Traumatic Brain Injury (mTBI) and chronic cognitive impairment: A scoping review.(Research Article). PLoS ONE. 2017;12(4):e0174847.

5. Xiong Y, Mahmood A, Chopp M. Animal models of traumatic brain injury. Nat Rev Neurosci. 2013;14(2):128-42.

6. Mao H, Guan F, Han X, Yang KH. Strain-based regional traumatic brain injury intensity in controlled cortical impact: a systematic numerical analysis. Journal of Neurotrauma. 2011;28:2263+.

7. Mao H, Lu L, Bian K, Clausen F, Colgan N, Gilchrist M. Biomechanical analysis of fluid percussion model of brain injury. 2018;77.

8. Cole JT, Yarnell A, Kean WS, Gold E, Lewis B, Ren M, et al. Craniotomy: True Sham for Traumatic Brain Injury, or a Sham of a Sham? Journal of Neurotrauma. 2010;28(3):359-69.

9. Namjoshi DR, Cheng WH, McInnes KA, Martens KM, Carr M, Wilkinson A, et al. Merging pathology with biomechanics using CHIMERA (Closed-Head Impact Model of Engineered Rotational Acceleration): a novel, surgery-free model of traumatic brain injury. Molecular Neurodegeneration. 2014;9(1).

10. Bolton Hall AN, Joseph B, Brelsfoard JM, Saatman KE. Repeated Closed Head Injury in Mice Results in Sustained Motor and Memory Deficits and Chronic Cellular Changes.(Report). PLoS ONE. 2016;11(7).

11. Fievisohn EM, Sajja VSSS, Vandevord PJ, Hardy WN. Evaluation of Impact-Induced Traumatic Brain Injury in the Göttingen Minipig Using Two Input Modes. Traffic Injury Prevention: Peer-Reviewed Journal for the 58th Annual Scientific Conference of the 
Association for the Advancement of Automotive Medicine (AAAM), October 2014. 2014;15(S1):S81-S7.

12. Lindstedt S. Body Size, Physiological Time, and Longevity of Homeothermic Animals. Quarterly Review of Biology - QUART REV BIOL. 1981;56.

13. Armstrong E. A look at relative brain size in mammals. Neurosci Lett. 1982;34(2):101-4.

14. Ommaya AK, Hirsch AE, Yarnell P, Harris EH. Scaling of experimental data on cerebral concussion in sub-human primates to concussion threshold for man. DAVID W TAYLOR NAVAL SHIP RESEARCH AND DEVELOPMENT CENTER BETHESDA MD ...; 1967.

15. Bowen IG, Fletcher ER, Richmond DR, Defense Atomic Support A. Estimate of man's tolerance to the direct effects of air blast. Albuqueque, NM: Lovelace Foundation for Medical Education and Research; 1968.

16. Wood G, Panzer M, Yu A, Rafaels KA, Matthews KA, Bass CR. Scaling in blast neurotrauma. 2013 IRCOBI Conference Proceedings - International Research Council on the Biomechanics of Injury. 2013:549-58.

17. Takhounts EG, Eppinger RH, Campbell JQ, Tannous RE, Power ED, Shook LS. On the Development of the SIMon Finite Element Head Model. Stapp Car Crash J. 2003;47:107-33.

18. Jean A, Nyein MK, Zheng JQ, Moore DF, Joannopoulos JD, Radovitzky R. An animal-to-human scaling law for blast-induced traumatic brain injury risk assessment. Proceedings of the National Academy of Sciences. 2014;111(43):15310.

19. Saunders R, Tan XG, Bagchi A. On the Development of Interspecies Traumatic Brain Injury Correspondence Rules. Military Medicine. 2019;184(Supplement_1):181-94.

20. Wu T, Antona-Makoshi J, Alshareef A, Giudice JS, Panzer MB. Investigation of Cross-Species Scaling Methods for Traumatic Brain Injury Using Finite Element Analysis. Journal of Neurotrauma. 2019.

21. Mao H, Zhang L, Jiang B, Genthikatti VV, Jin X, Zhu F, et al. Development of a finite element human head model partially validated with thirty five experimental cases. J Biomech Eng. 2013;135(11):111002.

22. Mao H, Gao H, Cao L, Genthikatti VV, Yang KH. Development of high-quality hexahedral human brain meshes using feature-based multi-block approach. Comput Methods Biomech Biomed Engin. 2013;16(3):271-9. 
23. Chen Y, Mao H, Yang KH, Abel T, Meaney DF. A modified controlled cortical impact technique to model mild traumatic brain injury mechanics in mice. Frontiers in neurology. 2014;5:100.

24. Pleasant JM, Carlson SW, Mao H, Scheff SW, Yang KH, Saatman KE. Rate of neurodegeneration in the mouse controlled cortical impact model is influenced by impactor tip shape: implications for mechanistic and therapeutic studies. J Neurotrauma. 2011;28(11):2245-62.

25. Cater HL, Sundstrom LE, Morrison B. Temporal development of hippocampal cell death is dependent on tissue strain but not strain rate. Journal of Biomechanics. 2006;39(15):2810-8.

26. Bain AC, Meaney DF. Tissue-level thresholds for axonal damage in an experimental model of central nervous system white matter injury. J Biomech Eng. 2000;122(6):61522.

27. Rowson S, Brolinson G, Goforth M, Dietter D, Duma S. Linear and angular head acceleration measurements in collegiate football. J Biomech Eng. 2009;131(6):061016.

28. Rowson S, Duma SM, Beckwith JG, Chu JJ, Greenwald RM, Crisco JJ, et al. Rotational head kinematics in football impacts: an injury risk function for concussion. Ann Biomed Eng. 2012;40(1):1-13.

29. Rowson S, Beckwith JG, Chu JJ, Leonard DS. A six degree of freedom head acceleration measurement device for use in football. Journal of applied biomechanics. 2011;27(1):8-14.

30. Duma SM, Manoogian SJ, Bussone WR, Brolinson PG, Goforth MW, Donnenwerth $\mathrm{JJ}$, et al. Analysis of real-time head accelerations in collegiate football players. Clin J Sport Med. 2005;15(1):3-8.

31. Bian K, Mao H. Mechanisms and variances of rotation-induced brain injury: a parametric investigation between head kinematics and brain strain. 2020.

32. Bandak F, Eppinger R, Haffner M, Khaewpong N, Kuppa S, Maltese M, et al. Development of improved injury criteria for the assessment of advanced automotive restraint systems : II. 1999.

33. Eppinger RH, editor Prediction of thoracic injury using measurable experimental parameters. Proc 6th International Technical Conference on the Enhanced Safety of Vehicles; 1976.

34. Gentleman SM, Roberts GW, Gennarelli TA, Maxwell WL, Adams JH, Kerr S, et al. Axonal injury: a universal consequence of fatal closed head injury? Acta Neuropathol. 1995;89(6):537-43. 
35. Mao H, Yang KH, King AI, Yang K. Computational neurotrauma--design, simulation, and analysis of controlled cortical impact model. Biomech Model Mechanobiol. 2010;9(6):763-72.

36. Fijalkowski RJ, Stemper BD, Pintar FA, Yoganandan N, Crowe MJ, Gennarelli TA. New rat model for diffuse brain injury using coronal plane angular acceleration. $\mathbf{J}$ Neurotrauma. 2007;24(8):1387-98.

37. Fijalkowski RJ, Yoganandan N, Zhang J, Pintar FA. A finite element model of region-specific response for mild diffuse brain injury. Stapp Car Crash J. 2009;53:193213.

38. Takhounts EG, Craig MJ, Moorhouse K, McFadden J, Hasija V. Development of Brain Injury Criteria (BrIC). Stapp Car Crash Journal. 2013;57:243-66.

39. Knowles BM, Dennison CR. Predicting Cumulative and Maximum Brain Strain Measures From HybridIII Head Kinematics: A Combined Laboratory Study and PostHoc Regression Analysis. 2017;45(9):2146-58.

40. Gabler LF, Joodaki H, Crandall JR, Panzer MB. Development of a Single-Degree-ofFreedom Mechanical Model for Predicting Strain-Based Brain Injury Responses. Journal of Biomechanical Engineering. 2018;140(3).

41. Kleiven S. Predictors for Traumatic Brain Injuries Evaluated through Accident Reconstructions. Stapp Car Crash Journal. 2007;51:81-114.

42. MacManus DB, Pierrat B, Murphy JG, Gilchrist MD. Region and species dependent mechanical properties of adolescent and young adult brain tissue. 2017;7(1):13729.

43. MacManus DB, Pierrat B, Murphy JG, Gilchrist MD. Mechanical characterization of the P56 mouse brain under large-deformation dynamic indentation. 2016;6(1):21569.

44. Gefen A, Gefen N, Zhu Q, Raghupathi R, Margulies SS. Age-Dependent Changes in Material Properties of the Brain and Braincase of the Rat. Journal of Neurotrauma. 2003;20(11):1163-77.

45. Sauerbeck AD, Fanizzi C, Kim JH, Gangolli M, Bayly PV, Wellington CL, et al. modCHIMERA: a novel murine closed-head model of moderate traumatic brain injury. 2018;8(1):7677.

46. Chen K, Gu H, Zhu L, Feng D-F. A New Model of Repetitive Traumatic Brain Injury in Mice. Frontiers in Neuroscience. 2020;13(1417).

47. Morrison B, 3rd, Elkin BS, Dollé JP, Yarmush ML. In vitro models of traumatic brain injury. Annual Review of Biomedical Engineering. 2011;13:91-126. 
48. Vogel EW, 3rd, Panzer MB, Morales FN, Varghese N, Bass CR, Meaney DF, et al. Direct Observation of Low Strain, High Rate Deformation of Cultured Brain Tissue During Primary Blast. Annals of biomedical engineering. 2020;48(4):1196-206.

49. Atlan LS, Smith C, Margulies SS. Improved prediction of direction-dependent, acute axonal injury in piglets. Journal of neuroscience research. 2018;96(4):536-44.

50. Sullivan S, Friess SH, Ralston J, Smith C, Propert KJ, Rapp PE, et al. Behavioral deficits and axonal injury persistence after rotational head injury are direction dependent. Journal of neurotrauma. 2013;30(7):538-45.

51. Browne KD, Chen X-H, Meaney DF, Smith DH. Mild traumatic brain injury and diffuse axonal injury in swine. Journal of Neurotrauma. 2011;28:1747+.

52. Sullivan S, Eucker SA, Gabrieli D, Bradfield C, Coats B, Maltese MR, et al. White matter tract-oriented deformation predicts traumatic axonal brain injury and reveals rotational direction-specific vulnerabilities. 2015;14(4):877-96.

53. Laksari K, Wu LC, Kurt M, Kuo C, Camarillo DC. Resonance of human brain under head acceleration. Journal of the Royal Society, Interface. 2015;12(108):20150331-.

54. Stemper BD, Shah AS, Budde MD, Olsen CM, Glavaski-Joksimovic A, Kurpad SN, et al. Behavioral Outcomes Differ between Rotational Acceleration and Blast Mechanisms of Mild Traumatic Brain Injury. Frontiers in Neurology. 2016;7(31).

55. Sabet AA, Christoforou E, Zatlin B, Genin GM, Bayly PV. Deformation of the human brain induced by mild angular head acceleration. Journal of Biomechanics. 2008;41(2):307-15.

56. Cullen DK, Harris JP, Browne KD, Wolf JA, Duda JE, Meaney DF, et al. A Porcine Model of Traumatic Brain Injury via Head Rotational Acceleration. Methods in molecular biology (Clifton, NJ). 2016;1462:289-324. 


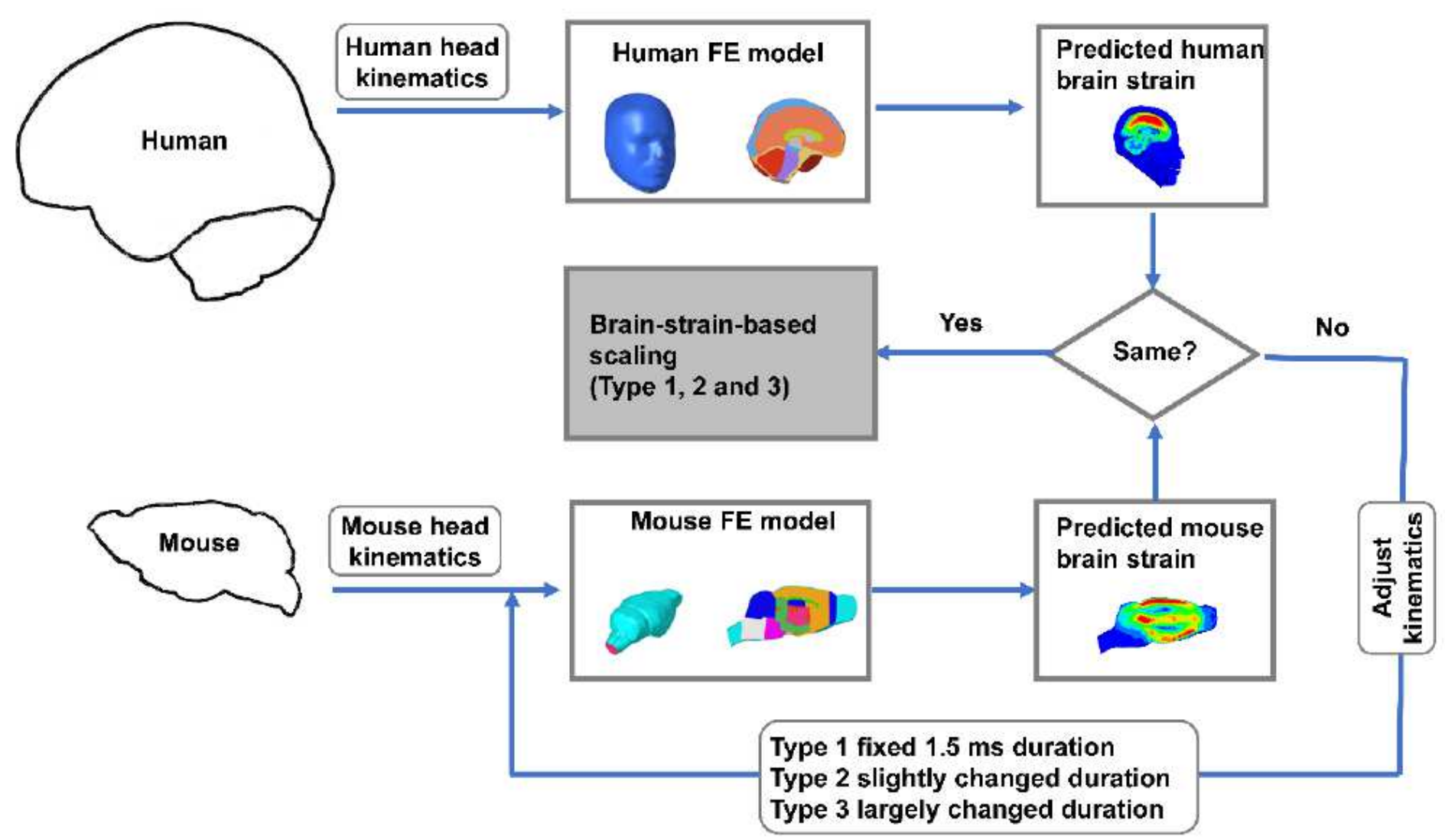

Figure 1

Workflow diagram represents methods in step how brain-strain-based scaling law was developed. Finite human brain and mouse brain finite element (FE) models were used to transfer head kinematics to brain strains. Three types of scaling with Type 1 indicating fixed $1.5 \mathrm{~ms}$ duration, Type 2 indicalting slightly changed duration, and Type 3 indicating larger changed duration. 


\section{Human brain strain}
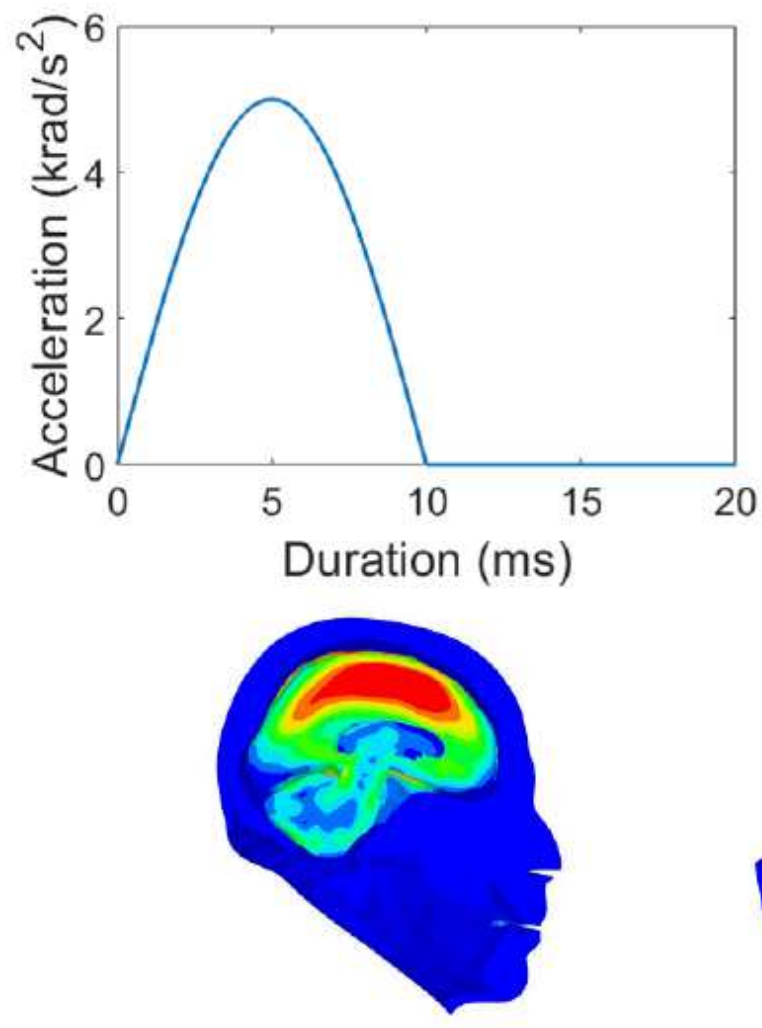

CSDM10 $=0.740$

\section{Brain mass-based scaling law \& Equal stress/velocity scaling law}

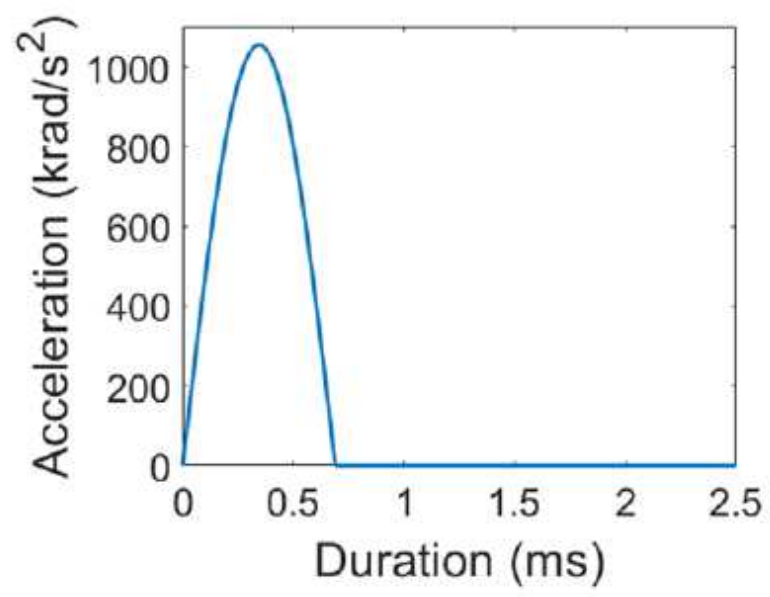

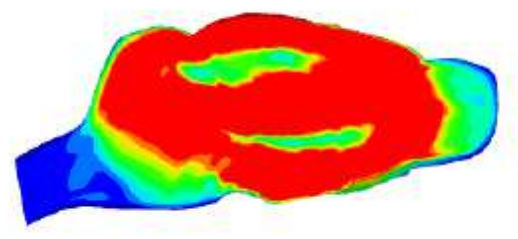

Original mouse brain model

CSDM10 $=0.954$

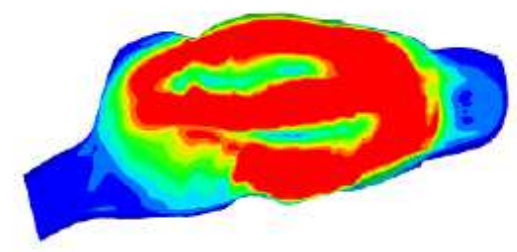

Human-material mouse brain model

CSDM10 $=0.947$

Strain scale 0.3

Figure 2

Evaluation of current scaling law. Applying traditional scaling induced larger strains in the mosue brain. 


\section{Peak rotational velocity VS. Brain strain responses}
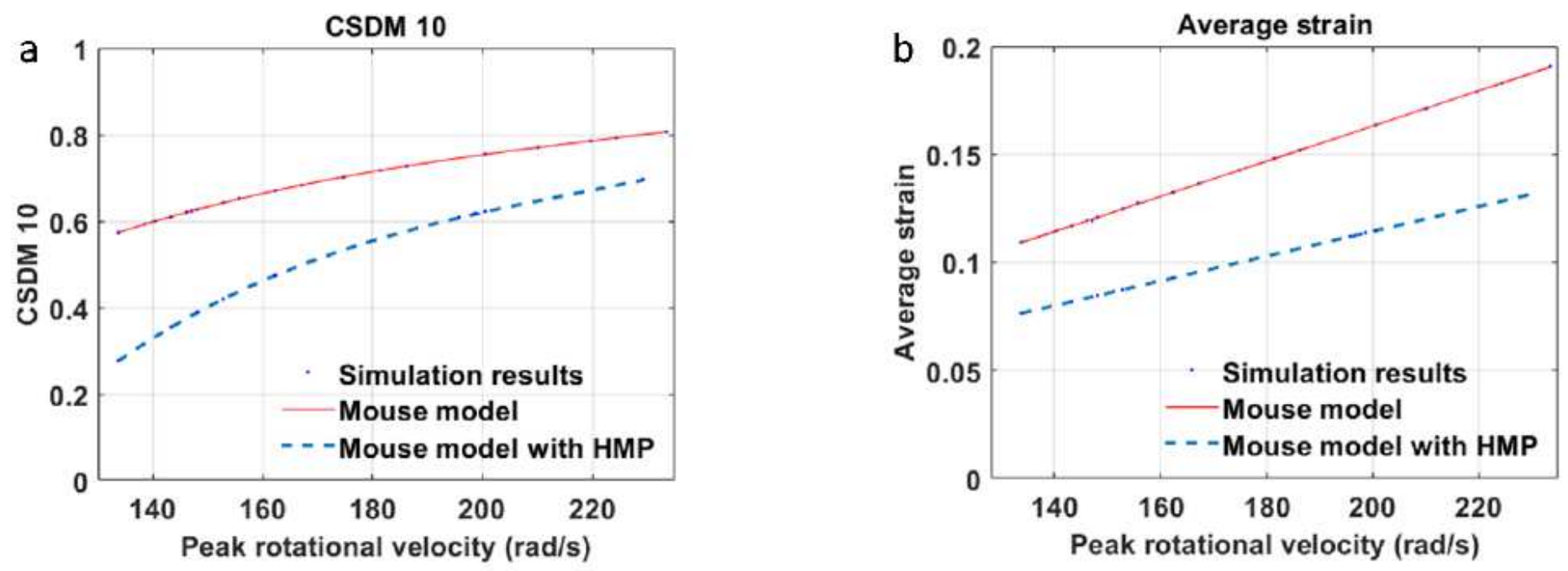

\section{Duration VS. Brain strain responses}
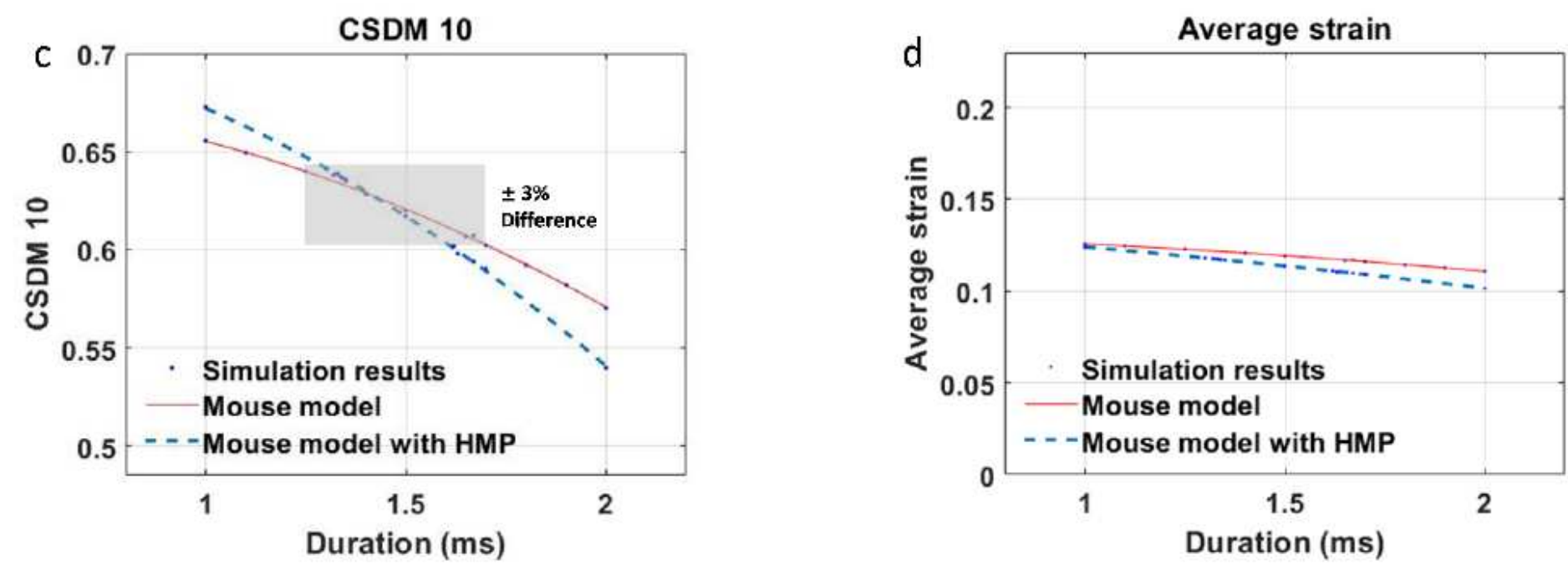

Figure 3

Relations between CSDM10, velocity and loading duration. The strain contour diagrams in the middle come from mouse model simulation results. (a) \& (b) Model predicted CSDM10 and average strain increases with peak rotational velocity when the duration is set to be constant as $1.5 \mathrm{~ms}$ in both the mouse model and the modified mouse model. (c) \& (d) Model predicted CSDM10 and average strain slightly decreases with the peak rotational velocity being set to be constant as $146 \mathrm{rad} / \mathrm{s}$ in the mouse model and $199 \mathrm{rad} / \mathrm{s}$ in the modified mouse model. 


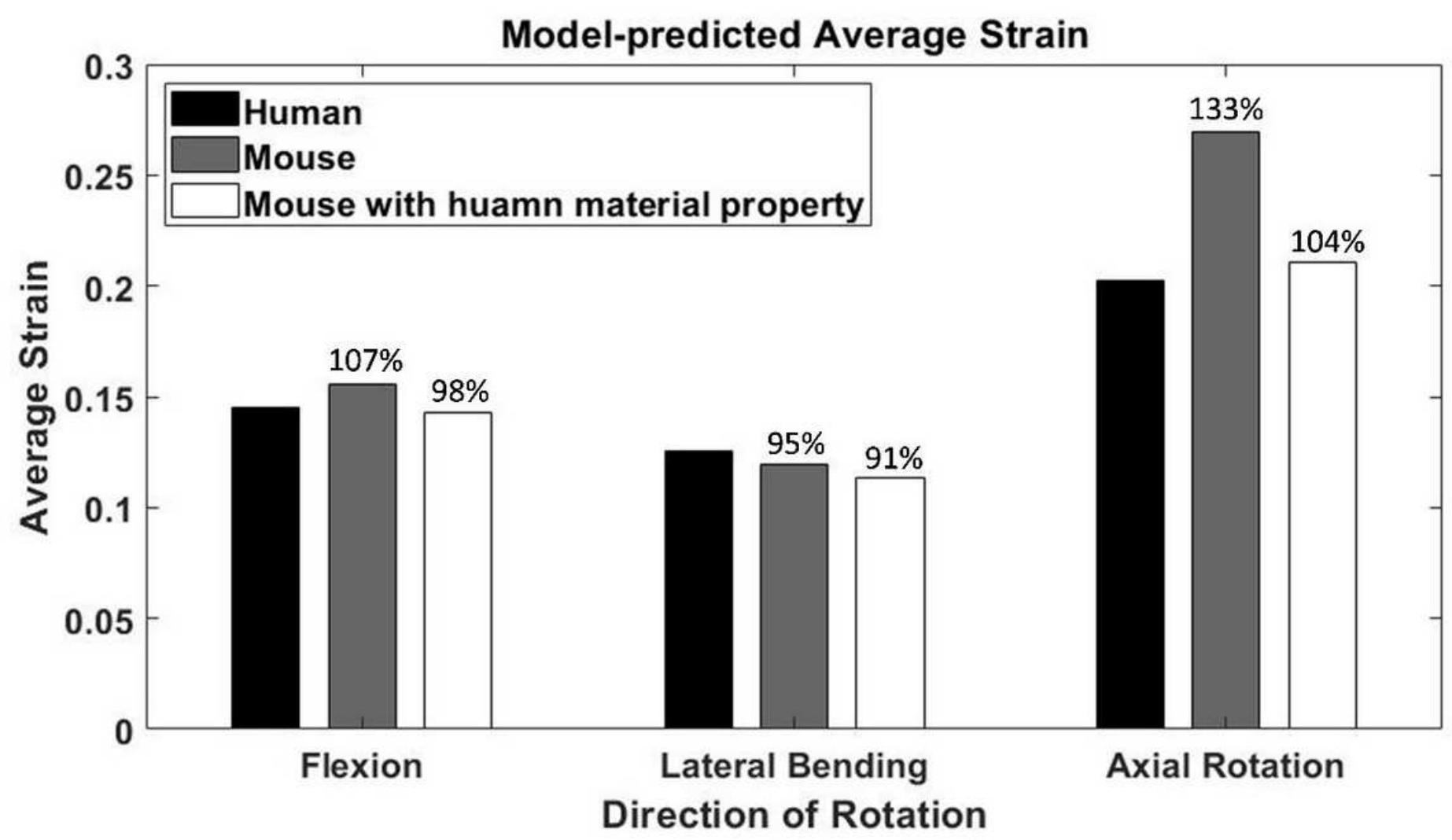

Figure 4

The comparison of predicted average strain between human, mouse and modified mouse models. The average strain around 0.15 indicates the injury severity is mild. 

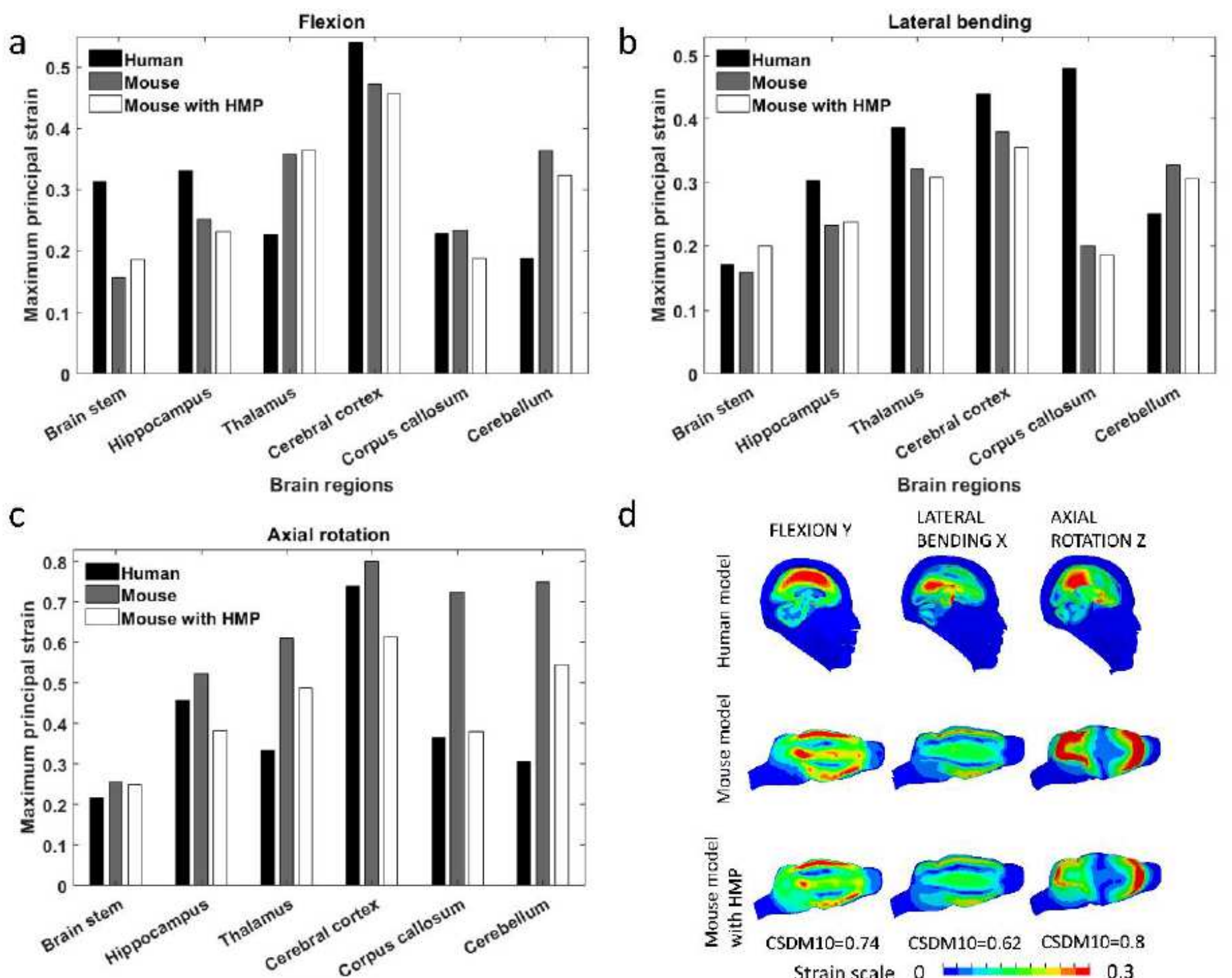

d Brain regions

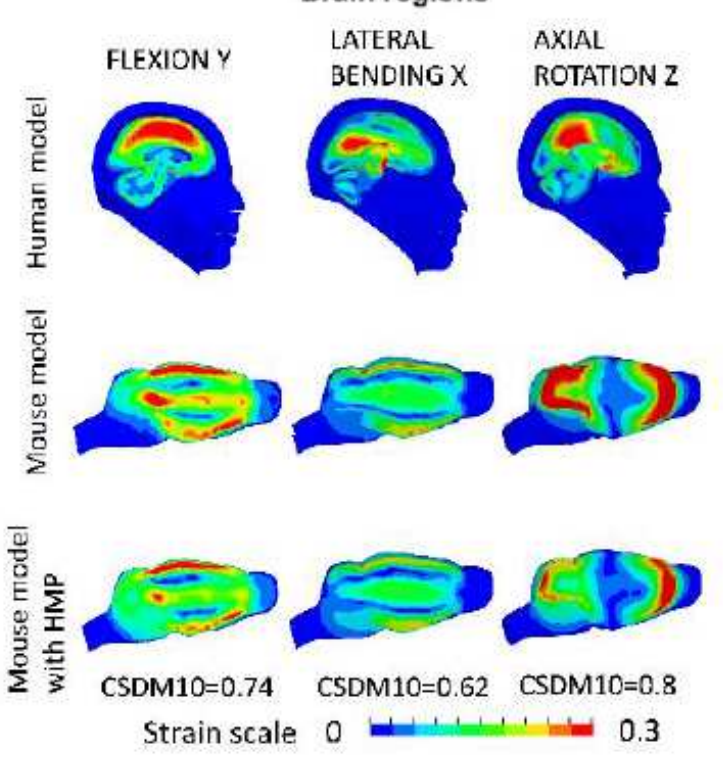

Brain regions

Figure 5

(a)(b)(c) Maximum principal strains for various brain regions in three rotational orientations including flexion, lateral bending, and axial rotation, respectively. (d) Predicted strain contour diagram of three models in three rotational orientations. 
a

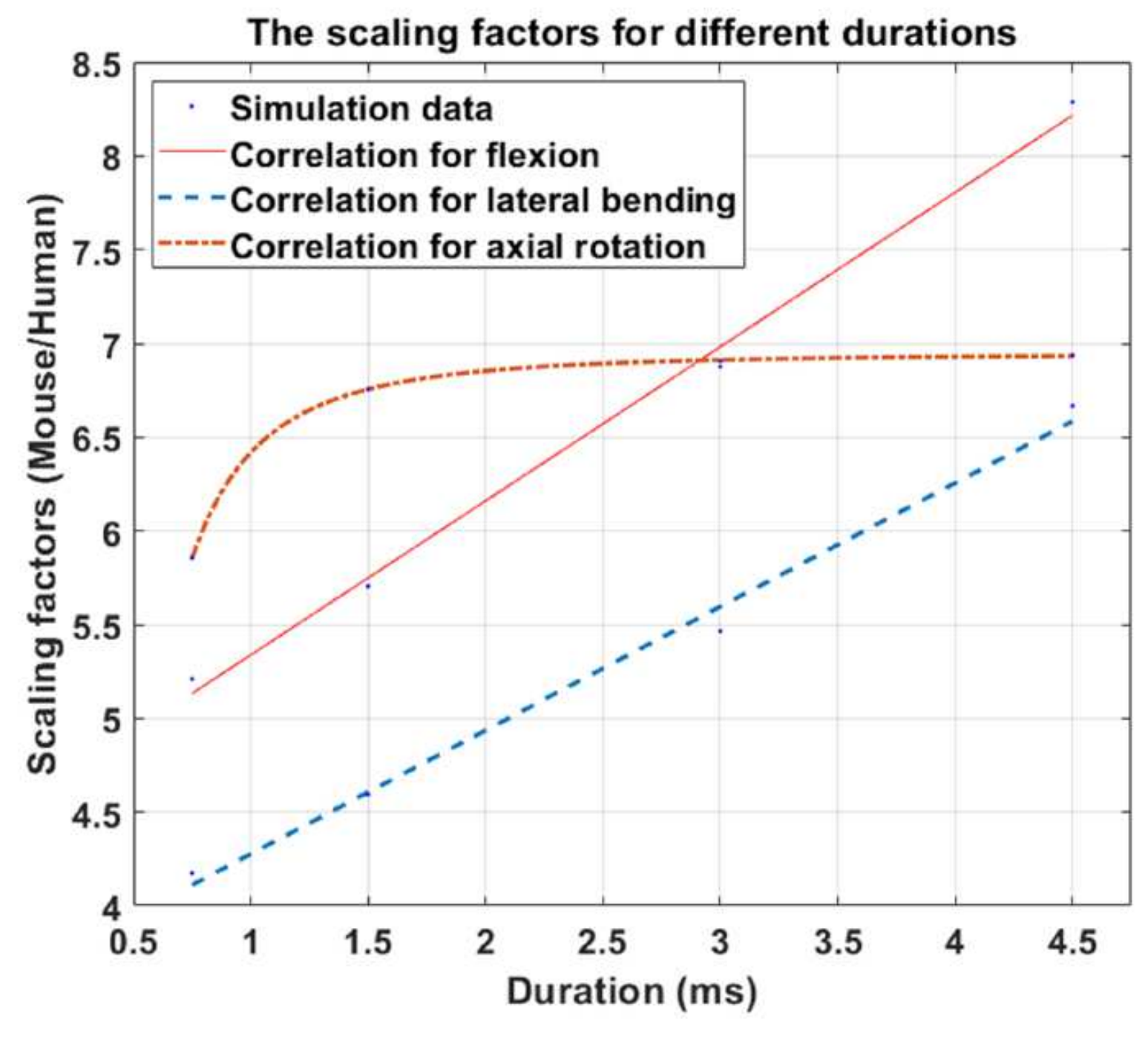

\begin{tabular}{c|c|c|c|c|c}
\hline \multicolumn{2}{c|}{ Duration (ms) } & 0.75 & 1.5 & 3 & 4.5 \\
\hline \multirow{2}{*}{$\begin{array}{c}\text { Scaling } \\
\text { factor } \\
(\mathrm{M} / \mathrm{H})\end{array}$} & $\mathrm{F}^{\mathrm{b}}$ & 5.2 & 5.8 & 6.9 & 8.3 \\
\cline { 2 - 6 } & $\mathrm{L}^{\mathrm{c}}$ & 4.2 & 4.6 & 5.5 & 6.7 \\
\cline { 2 - 6 } & $\mathrm{A}^{\mathrm{d}}$ & 5.9 & 6.8 & 6.9 & 6.9 \\
\hline
\end{tabular}

Note. ${ }^{2} \mathrm{M}=$ Mouse (Peak rotational velocity), $\mathrm{H}=$ Human (Peak rotational velocity); ${ }^{b} \mathrm{~F}=$ Flexion; ${ }^{c} \mathrm{~L}=$ Lateral bending; ${ }^{\mathrm{d}} \mathrm{A}=$ Axial rotation

Figure 6

The effect of duration during flexion loading. a) Scaling number increases linearly with duration. b) Summary of scaling factors for different durations. 